\title{
Tropical cyclone characteristics associated with extreme precipitation in the northern Philippines
}

Article

Published Version

Creative Commons: Attribution 4.0 (CC-BY)

Open Access

Racoma, B. A. B., Klingaman, N. P. ORCID:

https://orcid.org/0000-0002-2927-9303, Holloway, C. E.

ORCID: https://orcid.org/0000-0001-9903-8989, Schiemann, R. K. H. ORCID: https://orcid.org/0000-0003-3095-9856 and Bagtasa, G. (2021) Tropical cyclone characteristics associated with extreme precipitation in the northern Philippines. International Journal of Climatology. ISSN 1097-0088 doi: https://doi.org/10.1002/joc.7416 Available at https://centaur.reading.ac.uk/100722/

It is advisable to refer to the publisher's version if you intend to cite from the work. See Guidance on citing.

To link to this article DOI: http://dx.doi.org/10.1002/joc.7416

Publisher: Wiley

All outputs in CentAUR are protected by Intellectual Property Rights law, including copyright law. Copyright and IPR is retained by the creators or other copyright holders. Terms and conditions for use of this material are defined in the End User Agreement. 


\section{www.reading.ac.uk/centaur}

\section{CentAUR}

Central Archive at the University of Reading

Reading's research outputs online 


\title{
Tropical cyclone characteristics associated with extreme precipitation in the northern Philippines
}

\author{
Bernard Alan B. Racoma ${ }^{1,2}$ () | Nicholas P. Klingaman ${ }^{3}$ ( ) |

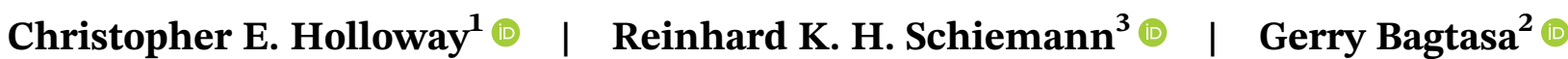

${ }^{1}$ Department of Meteorology, University of Reading, Reading, UK

${ }^{2}$ Institute of Environmental Science and Meteorology, University of the

Philippines, Diliman, Quezon City, Philippines

${ }^{3}$ National Centre for Atmospheric Science, Department of Meteorology, University of Reading, Reading, UK

\section{Correspondence}

Bernard Alan B. Racoma, Institute of Environmental Science and Meteorology, University of the Philippines, Diliman, P. Velasquez Street, Quezon City, 1101, National Capital Region, Philippines. Email: bbracoma@up.edu.ph

\section{Funding information}

Independent Research Fellowship from the Natural Environment Research Council and by the National Centre for Atmospheric Science Atmospheric Hazards in Development Countries: Risk Assessment and Early Warning (ACREW) programme. Grant/Award Number: NE/L010976/1.

\begin{abstract}
The Philippines is exposed to tropical cyclones (TCs) throughout the year due to its location in the western North Pacific. While these TCs provide muchneeded precipitation for the country's hydrological cycle, extreme precipitation from TCs may also cause damaging hazards such as floods and landslides. This study examines the relationship between TC extreme precipitation and TC characteristics, including movement speed, intensity and season, for westward-moving TCs crossing Luzon, northern Philippines. We measure extreme precipitation by the weighted precipitation exceedance (WPE), calculated against a 95th percentile threshold, which considers both the magnitude and spatial extent of TC-related extreme precipitation. WPE has a significant, moderate positive relationship with TC intensity with a non-significant, weak negative relationship with movement speed. When TCs are classified by intensity 1 day before landfall (or pre-landfall), Typhoons (1-min maximum sustained wind speed $\geq 64$ knots) tend to yield higher WPE than non-Typhoons ( $<64$ knots). On the other hand, when TCs are classified by pre-landfall speed, slow TCs (movement speed $<11.38$ knots) tend to yield higher WPE than fast TCs (movement speed $\geq 11.38$ knots). However, the relationship between prelandfall TC intensity and WPE is more pronounced during June-September while there is no significant difference between the WPE of the southwest monsoon (June-September) and northeast monsoon (October-December) seasons. These results suggest that it is important to consider the pre-landfall cyclone movement speed, intensity and season to anticipate extreme precipitation of incoming TCs. A decision table considering these factors is devised to aid in TC extreme precipitation forecasting.
\end{abstract}

\section{K E Y W O R D S}

extreme precipitation, Philippines, precipitation, tropical cyclone intensity, tropical cyclone movement speed, tropical cyclones, Typhoons 


\section{INTRODUCTION}

The Philippines is in the southwestern portion of the western North Pacific (WNP) basin, the most active tropical cyclone (TC) basin. As such, the country experiences many TCs every year. According to Cinco et al. (2016), between 1951 and 2013, an average of nine TCs per year made landfall in the Philippines. Besides the wind hazards that these TCs pose, they also bring substantial rainfall to the country. For Luzon, the northern region of the Philippines, $40 \%$ of the total yearly rainfall is caused by TCs (Bagtasa, 2017). Rain from TCs is a very important resource to support Philippine agriculture, with $41.7 \%$ of the country's total land area dedicated to permanent crops and pastures (World Bank, 2015). While TCs bring much needed rain, extremely intense rainfall from TCs causes hazards, such as floods, landslides and debris flows.

Cinco et al. (2016) report that between 1971 and 2013, TCs cost the Philippines 440.5 billion Philippine pesos (51.7958 Philippine pesos $=1$ US Dollar in 2019) in total damages. One example of devastating TCs is tropical storm Ketsana in 2009, where gauge-recorded precipitation reached as much as $413 \mathrm{~mm}$ in $9 \mathrm{hr}$, triggering exceptional floods causing 2 billion Philippine pesos worth of property and infrastructure damage (Abon et al., 2011). The torrential rains of Super Typhoon Bopha of 2012 similarly caused widespread flooding and debris flows in the New Bataan municipality of Mindanao, immediately burying and killing 566 people (Rodolfo et al., 2016). In December 2017, two consecutive TCs, tropical storms Kai-tak and Tembin, caused an unprecedented amount of rain in Visayas and Mindanao, the central and southern regions of the Philippines. According to Lagmay and Racoma (2019), Kai-tak brought a total of $571.5 \mathrm{~mm}$ in 3 days; during the following week, Tembin brought $297 \mathrm{~mm}$ in a similar timespan. These two consecutive TCs caused flash floods and landslides with 91 confirmed deaths and 199 people missing in Visayas and Mindanao (Lagmay and Racoma, 2019).

As such, anticipating and understanding extreme precipitation that TCs bring are of great interest. Previous TC-precipitation studies focused on Taiwan revealed that TCs with slower translation speeds tend to produce more rainfall (Hsu et al., 2013). Regardless of intensity, slower moving TCs will remain longer in a region and, thus, are associated with larger precipitation totals. Cheung et al. (2008) also noted that besides translation speeds, variations in TC track affect the spatial distribution of rainfall. They have proposed that TC rainfall prediction should be based on climatologically based statistical models of TC rainfall as well as persistence of an ongoing TC's 3-hr accumulated precipitation to augment model forecasts. Kossin (2018) suggests that the global slowing of TCs due to atmospheric warming caused by anthropogenic climate change may increase TC-related rainfall in the future as TC-related rainfall depends on both rain rate and translation speed. While the validity of the relationship between climate change and TC movement speed in Kossin (2018) is arguable due to the inhomogeneity of the best track data used (Lanzante, 2019; Moon et al., 2019; Yamaguchi et al., 2020), higher TC-related rainfall is generally associated with slower TC speeds due to the longer duration of a TC's influence over a region (Emanuel, 2017; Lai et al., 2020).

To our best knowledge, no previous study has analysed the statistical relationship between TC intensity or movement speed and precipitation in Luzon. Previous studies of Philippine TCs focused on long-term trends of TC activity (David et al., 2013; Cinco et al., 2016), impacts of the El Niño Southern Oscillation on inter-annual variability in TC activity (Corporal-Lodangco et al., 2016), precipitation enhancement due to TCs interacting with the monsoon (Cayanan et al., 2011; Bagtasa, 2019), the contribution of TC precipitation to total precipitation (Bagtasa, 2017) and case studies on the effect of topography on TC rainfall (Minamide and Yoshimura, 2014; Lagmay et al., 2015; Racoma et al., 2016).

Methods for predicting extreme rainfall and hydrological hazards associated with landfalling TCs still need improvement. Cheung et al. (2018) previously discussed Super Typhoons Nepartak and Meranti affecting China in 2016. These TCs had similar characteristics yet caused very different impacts. While both TCs had similar strengths and made similar landfall locations, Nepartak only caused localized thunderstorms while Meranti caused widespread rainfall along the Taihu Lake Basin (Cheung et al., 2018). While some progress is being made in understanding internal rainfall dynamics of TCs in forecasts through numerical weather prediction (NWP) models (Cheung et al., 2018), estimating incoming TC precipitation using NWP models is computationally expensive. NWP models also exhibit biases and errors in predicting TC-related rainfall, resulting from limited horizontal resolution and errors in sub-gridscale physical parameterizations. For example, the Met Office NWP model shows significant dry biases in predicting TC-related precipitation over Luzon and Visayas (Peatman et al., 2019).

This paper takes a different approach through analysing the probability that an incoming TC will be associated with widespread extreme precipitation based on the characteristics of historical TCs. Understanding how extreme TC precipitation is related to characteristics such as season, movement speed and intensity will be helpful in predicting the possible impacts of future TCs. These 
observed relationships will also provide a benchmark against which to evaluate model simulations of TCs and their impacts over the Philippines.

We analyse a region encompassing the northern and central parts of Luzon (hereafter referred to as Luzon). Figure 1 shows the topographic map of Luzon generated using elevation data from the NASADEM Merged DEM Global 1 arc sec dataset (NASA JPL, 2020). Luzon is located in the northern Philippines and is bordered by the Cordillera Central to the northwest (Figure 1a), the Zambales mountain range towards the southwest (Figure 1b), the Sierra Madre mountain range spanning north to south in the east (Figure 1c,d) and the volcanic region of Batangas towards the south. Due to its large land area and location, $20.2 \%$ of all TCs that form in the WNP basin cross the general region of Luzon (David et al., 2013; Cinco et al., 2016). Similarly, the contribution of TC rainfall to the annual total is highest (nearly 50\%) in this portion of the Philippines (Cinco et al., 2016; Bagtasa, 2017). To mitigate the impact of TCs that make landfall in the region, it is of great interest to anticipate their possible associated precipitation through relationships with TC intensity and movement speed, while considering the associated season.

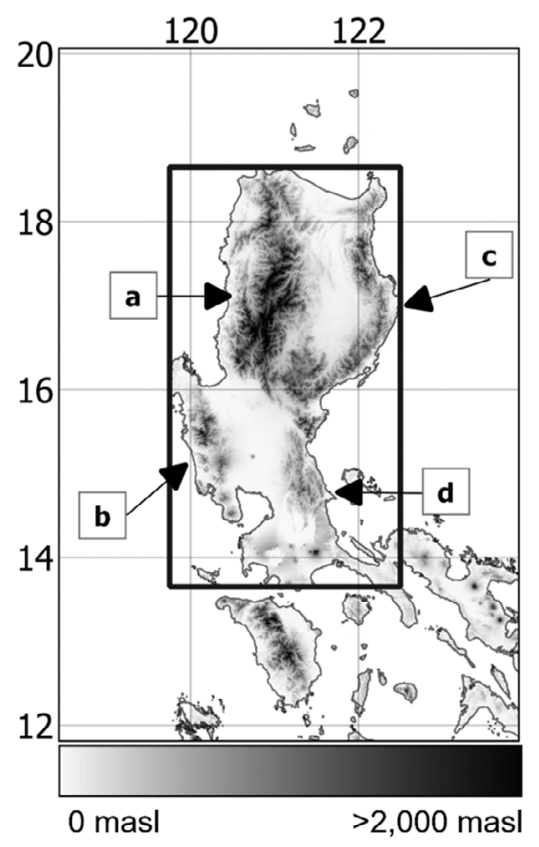

FIGURE 1 Topographic map of the northern and central regions of Luzon with the black arrows indicating the general regions of (a) the Cordillera Central mountain range, (b) Zambales mountain range and the (c) northern and (d) southern portion of the Sierra Madre mountain range. Darker shades show higher elevations (metres above sea level, masl). The study region is enclosed in the box. Elevation is taken from the NASADEM merged DEM global 1 arc sec dataset (NASA JPL, 2020)

\section{2 | DATA AND METHODOLOGY}

\section{$2.1 \quad$ TC data and climatology}

Data such as time, date, location, intensity and movement speed of TCs that made landfall in Luzon were taken from the International Best Track Archive for Climate Stewardship (IBTrACS) database. IBTrACS aims to collect the historical TC best-track data from all available agencies (Knapp et al., 2010). As of IBTrACS v04, TC characteristics are available every $3 \mathrm{hr}$ (Knapp et al., 2018), with intensity data from some agencies available beginning in 1978. For precipitation, we used data from the Asian Precipitation-Highly-Resolved Observational Data Integration Towards Evaluation (APHRODITE; Yatagai et al., 2012) V1101 and V1101EX. The APHRODITE record ends in 2015; hence, we select all TCs between 1978 and 2015 to ensure availability of intensity data and precipitation data. As the APHRODITE dataset records precipitation on a daily basis, for the purposes of comparison with a higher temporal resolution dataset, we also used precipitation data from the Tropical Rainfall Measuring Mission (TRMM) 3B42, version 7 (Huffman et al., 2007; TRMM, 2011).

We then selected TCs between June and December to coincide with the monsoon seasons in the Philippines. According to Cruz et al. (2013), the southwest monsoon (local name Habagat) typically lasts from June to September (JJAS). On the other hand, the northeast monsoon (local name Amihan) lasts from October to December (OND). The average monthly number of TCs making landfall in Luzon increases in June, decreases by August and September, increases by October and then finally tapers off by December (Figure 2).

We select all TCs from the WNP that cross the study region (enclosed in box in Figure 1) with a general westward direction (or a bearing between $180^{\circ}$ and $360^{\circ}$ angle from north) upon making first landfall on the eastern coast of Luzon north of $13.5^{\circ} \mathrm{N}$. This is done to create a TC dataset with similar paths upon landfall. This also eliminates TCs that move eastward or stay across the region for longer periods due to the Fujiwhara effect (Fujiwhara, 1923). Similarly, eastwardmoving TCs originating in the South China Sea were also not included in the dataset. A total of 127 TCs were included in this study, with Figure 3 showing the TC track points 1 day $(24 \mathrm{hr}$ ) before making landfall in diamonds, 1 day after making landfall (including the earliest instance of landfall) in squares and all the other TC points in as dots.

\section{2 | Measuring extreme precipitation for each TC}

To evaluate historical precipitation extremes as well as precipitation during TC events, we use the APHRODITE 
Total monthly tropical cyclone landfalls

in the Philippines and in Luzon, 1978-2015

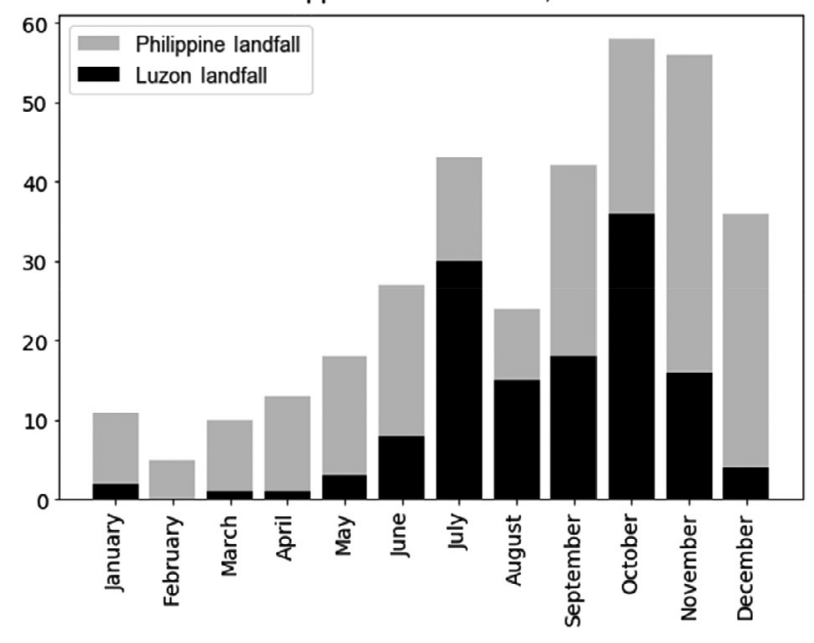

F I G U RE 2 Total monthly number of TC landfalls in Luzon (black) and in the Philippines (black and grey combined) between 1978 and 2015. These are calculated from IBTrACS. Only westward travelling TCs are included

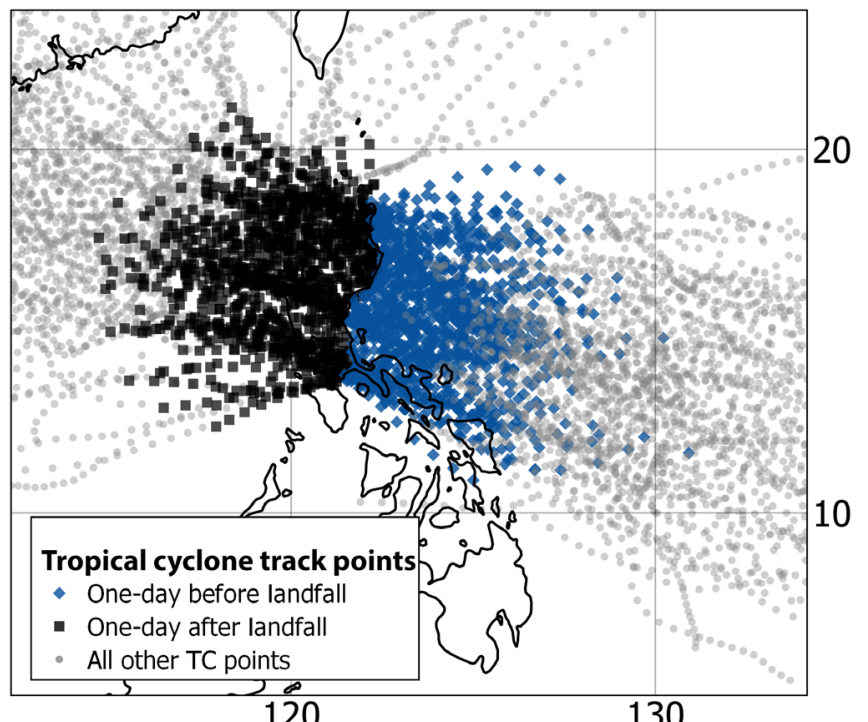

F I G U RE 3 Three-hourly track points of TCs included in this study, with the points 1 day before landfall in blue diamonds, 1 day after landfall (starting at time of landfall) in black squares and all other points in grey circles. Data are from IBTRACS [Colour figure can be viewed at wileyonlinelibrary.com]

Monsoon Asia versions V1101 and V1101EX. APHRODITE offers daily gridded precipitation at a spatial resolution of $0.25^{\circ}$ latitude/longitude between 1951 and 2007 for V1101, with V1101EX extending this to 2015. The APHRODITE gridded data are derived by interpolating daily precipitation from a dense network of observation stations across Asia using an interpolation method that considers a region's climatology and topography to fill gaps between stations (Yatagai et al., 2012). To evaluate the usefulness of APHRODITE in the Philippine context, Jamandre and Narisma (2013) found high correlations for daily precipitation between an older version of APHRODITE (V1003R1) and station data during June and November. The study also showed that APHRODITE has high spatial correlation in Luzon with different satellite products such as TRMM and Climate Prediction Centre morphing method (CMORPH).

According to Kubota and Wang (2009), on average, a TC's precipitation is mainly limited to a $1,000 \mathrm{~km}$ radius from the TC centre. Bagtasa (2017) also used a similar measure of radius of TC-induced rainfall at $10^{\circ}$ latitude/ longitude $(\sim 1,110 \mathrm{~km})$. For the TCs selected in this study, the median distance between the nearest coast of Luzon and the TC points $24 \mathrm{hr}$ before landfall is $205.73 \mathrm{~km}$, while the median distance for TC points $24 \mathrm{hr}$ after landfall is $46.32 \mathrm{~km}$. This means for most TCs in this study, Luzon is well within the $1,000 \mathrm{~km}$ range of a TC's radius of precipitation.

Precipitation for each TC was then calculated in Luzon (between 13.00 and $18.65^{\circ} \mathrm{N}$ and 119.75 and $122.50^{\circ} \mathrm{E}$ ) by collecting the $48 \mathrm{hr}$ of TC points centred on the first landfall (blue diamonds and black squares in Figure 3) to account for direct TC rain from rain bands before and after landfall. The date of each three-hourly TC point was then matched with their corresponding daily APHRODITE precipitation. To account for a TC spanning different dates during the $48 \mathrm{hr}$ (and hence different daily APHRODITE precipitation fields), daily APHRODITE precipitation for each grid point was converted to 3-hr values by assuming uniformly distributed precipitation within the day (hereafter referred to as $\mathrm{APHRO}_{\text {uniform}}$ ). Afterwards, the total precipitation for the $48 \mathrm{hr}$ centred on TC landfall is accumulated from the 3-hr values.

As $\mathrm{APHRO}_{\text {uniform }}$ is derived from a daily precipitation dataset, it is possible there is a reduction of the signal of extreme precipitation by assuming a uniformly distributed precipitation throughout the 48 -hr period. Due to this limitation, the higher temporal resolution threehourly precipitation records of TRMM 3B42, version 7, hereafter $\mathrm{TRMM}_{3 \mathrm{hr}}$, were also considered for this study. However, as $\mathrm{TRMM}_{3 \mathrm{hr}}$ is only available between 1998 and 2019, this considerably reduces the number of TCs that we can analyse from 127 to 75 .

To approximate the reduction of the signal of extreme precipitation by assuming a uniformly distributed precipitation for a daily dataset, we evaluated three precipitation datasets: $\mathrm{APHRO}_{\text {uniform }}, \mathrm{TRMM}_{\text {uniform }}$ (derived from the daily TRMM 3B42, version 7) and $\mathrm{TRMM}_{3 \mathrm{hr}}$. $\mathrm{TRMM}_{\text {uniform }}$ was calculated similar to $\mathrm{APHRO}_{\text {uniform }}$ by distributing the 48-hr accumulated precipitation uniformly in three-hourly segments. For $\mathrm{APHRO}_{\text {uniform }}$, 
$\mathrm{TRMM}_{3 \mathrm{hr}}$ and $\mathrm{TRMM}_{\text {uniform}}$, precipitation was calculated by accumulating precipitation for the $48-\mathrm{hr}$ period centred on TC landfall for each TC in 1998-2015 (totalling to $51 \mathrm{TCs}$ ). Afterwards, the mean precipitation across the grid was taken to compare the datasets.

We see from Figure $\mathrm{S} 1$ that while $\mathrm{TRMM}_{\text {uniform }}$ yields higher precipitation than $\mathrm{APHRO}_{\text {uniform }}$, the two datasets are positively correlated $(r=.73$ and $p<.001)$ with a slope of 1.52. Consistent with the results of Jamandre and Narisma (2013), TRMM, in general, tends to yield higher estimates compared to APHRODITE. As such, as long as the difference in magnitude is considered, this shows that both daily datasets behave similarly in terms of measuring precipitation for TC events.

We then compared 48-hr precipitation derived from the same data source recorded at different time intervals: $\mathrm{TRMM}_{3 \mathrm{hr}}$ with $\mathrm{TRMM}_{\text {uniform. It can be seen from }}$ Figure S2 that $\mathrm{TRMM}_{3 \mathrm{hr}}$ and $\mathrm{TRMM}_{\text {uniform }}$ show a statistically significant positive correlation $(r=.99$ and $p<.001)$ with a slope of 1.08. TRMM $\mathrm{uniform}_{\text {is also }}$ biased towards the lower range, with the lower precipitation estimates of $\mathrm{TRMM}_{\text {uniform }}$ much nearer to the values of $\mathrm{TRMM}_{3 \mathrm{hr}}$. As the values of TRMM $3 \mathrm{hr}$ on average are only $5 \%$ higher than $\mathrm{TRMM}_{\text {uniform}}$, we determined that assuming a uniformly distributed precipitation throughout the day for a daily dataset does not significantly reduce the signal for the occurrence of extreme precipitation.

The previous analysis shows that while some signals for extreme precipitation are indeed reduced in a uniformly distributed daily dataset, it is still acceptable for use in our study. Similarly, besides significantly reducing the number of TCs included, using TRMM $\mathrm{TMh}_{3 \mathrm{hr}}$ in our analysis did not affect our observations and conclusions.
While we continued to use APHRODITE to ensure that we are able to analyse a higher number of TCs, for the purposes of completeness and comparison, we also proceeded with calculations of extreme precipitation using $\mathrm{TRMM}_{3 \mathrm{hr}}$.

Several studies report a detectable diurnal variation of TC precipitation (e.g., Bowman and Fowler, 2015). Thus, we initially considered diurnal adjustments to the 3-hr APHRODITE precipitation. However, previous studies on the diurnal precipitation of TCs mostly focused on TCs over the ocean (Wu et al., 2015; Leppert and Cecil, 2016; Rios Gaona and Villarini, 2018). While Nesbitt and Zipser (2003) reported a marked afternoon rainfall maximum for TCs over land, according to idealized studies by O'Neill et al. (2017), the weakening of TCs upon making landfall further complicates establishing this diurnal cycle. We tested a simple diurnal scheme, with a sinusoidally varying adjustment up to $30 \%$ of the daily mean, but this did not affect our conclusions. Based on that result, and the uncertainty in observation-based estimates of TC diurnal rainfall variability, we continued to assume uniformly distributed precipitation throughout the day.

While taking the mean TC-associated precipitation across grid points in Luzon is useful to measure rainfall volume, this does not necessarily represent extreme precipitation. Given the same area coverage, mean precipitation is sensitive to the spatial distribution of precipitation, particularly when high and focused precipitation is observed in a small region while little precipitation is recorded elsewhere. Rather than directly taking the mean precipitation, we calculate precipitation for each TC event against an extreme precipitation threshold. To establish this threshold, we adapt extreme precipitation as defined by Diffenbaugh et al. (2005), Guo
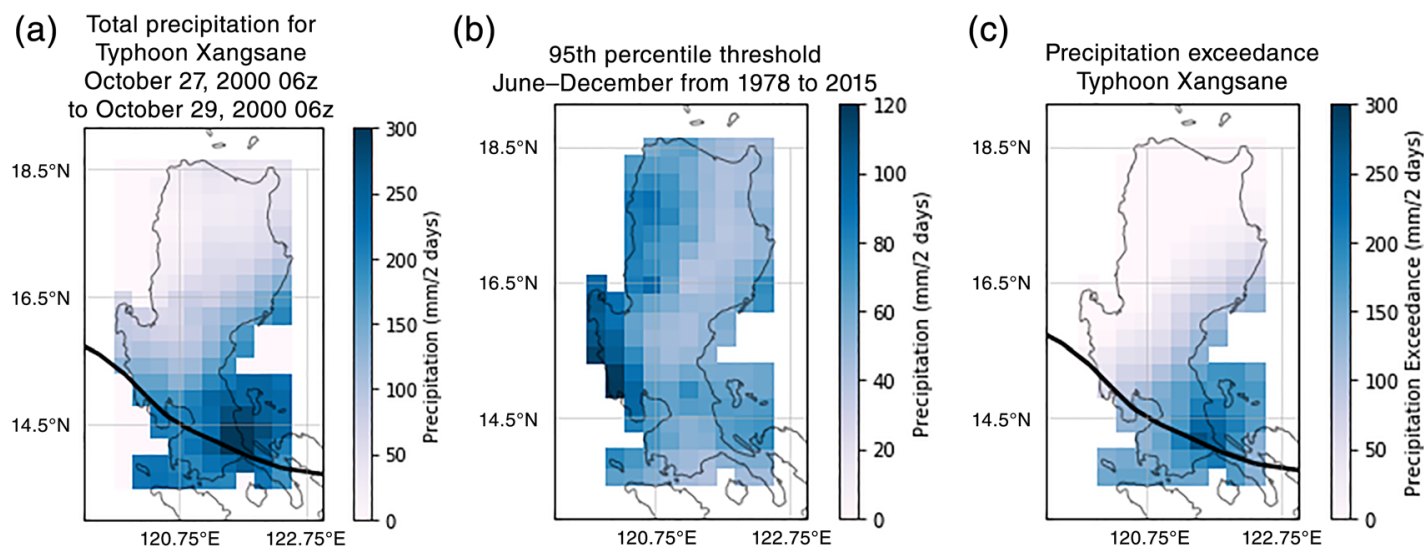

F I G U R E 4 Using APHRODITE, from the (a) accumulated precipitation for $48 \mathrm{hr}$ centred on landfall for Typhoon Xangsane, we subtract the (b) 95th percentile threshold to get the (c) precipitation exceedance with grid points where the precipitation that does not exceed the threshold is set to zero. WPE is then calculated by taking the area. Mean of the exceedance. Note that the scale is different for (b), the 95th percentile threshold. The track for this TC is shown in solid black lines, and the WPE for this TC is $61.00 \mathrm{~mm} / 2$ days [Colour figure can be viewed at wileyonlinelibrary.com] 
et al. (2017), and Kim et al. (2019) by calculating a twoday 95th percentile precipitation map using all two-day windows with recorded rainfall (precipitation $>0$ ) from June to December in 1978-2015. Any two-day accumulated precipitation that exceeds this local 95th percentile threshold is considered extreme precipitation.

From the extreme precipitation threshold, we then evaluated the weighted precipitation exceedance (WPE), for each of the TCs affecting Luzon. WPE is defined as the area mean of precipitation over Luzon that exceeds the local 95th percentile threshold (total precipitation minus 95th percentile threshold). Grid cells where precipitation does not exceed the 95th percentile (negative differences) are set to zero for the WPE calculation. This gives us a single value that reflects both the magnitude and spatial extent of the TC-associated precipitation that exceeds the 95th percentile. Due to the nature of the WPE calculation, any TC with positive WPE exceeds the 95th percentile threshold in at least some locations and, as such, is considered to produce extreme precipitation.

Figure 4 shows Typhoon Xangsane as an example to illustrate how WPE is calculated. Typhoon Xangsane was a particularly intense (1-min maximum sustained wind speed of 89 knots) TC that brought strong winds along with high amounts of rain in the Philippines, leaving 26 dead and 17 Million USD (in 2001 currency) worth of property and crop damage in its wake (Weather, 2001). Figure 4a shows the accumulated two-day precipitation during Typhoon Xangsane's landfall in Luzon (from October 27, 2000 06z to October 29, 2000 06z), while Figure $4 \mathrm{~b}$ shows the 95 th percentile precipitation threshold for all two-day windows with precipitation in the months of July-December for the years 1978-2015. The WPE of this TC is calculated by subtracting the precipitation threshold (Figure 4b) from the Typhoon's two-day precipitation (Figure 4a). Any negative values (or grid cells below the threshold) are set to zero, and the exceedance is shown in darker shades in Figure 4c. The areaweighted mean of all exceedances (including zeroes) is taken, and the calculated WPE for this TC is at $61.00 \mathrm{~mm} / 2$ days.

\section{3 | RESULTS}

\section{1 | Difference in TC precipitation and characteristics between JJAS and OND}

\subsection{1 | TC precipitation and tracks}

Figure 5 shows the seasonal mean two-day precipitation and the mean precipitation during the 2 days centred on landfall, as well as the TC tracks for JJAS and OND.
According to Akasaka et al. (2007), the western region of the Philippines has a distinct rainy season starting in the middle of May, peaking in August and withdrawing towards early November. This can be seen in the higher precipitation regions towards the west in JJAS (Figure 5a). Westward-moving TCs that make landfall in Luzon during JJAS (Figure 5c) tend to cause more precipitation towards western Luzon, particularly the western flanks of Cordillera Central with higher amounts along the Zambales mountain range in the southwest (Figure 5b). This spatial distribution of landfalling TC-related precipitation is similar to the seasonal mean during JJAS, albeit with much higher magnitudes. It is also consistent with the spatial distribution of TC-contributed rainfall in Bagtasa (2017), where TCs contribute as much as $50 \%$ of precipitation in western Luzon. The interaction between the monsoonal flow and TCs also results in enhanced convergence and ascent, leading to increased precipitation in western Luzon (Cayanan et al., 2011).

In contrast, mean two-day precipitation in OND is generally lower than in JJAS, except for higher amounts of rain towards the eastern portion of the southern Sierra Madre mountain range (Figure 5d). Akasaka et al. (2007) note that eastern Luzon experiences maximum rainfall in autumn and winter (starting from October) marked by the abrupt change from westerly to easterly winds around the Philippines. This eastward shift along with generally lower amounts of precipitation can also be attributed to the change from southwesterly moist flow from the Indian Ocean in summer to north-easterly cooler and drier air from the subtropical Pacific during winter (Ding and Chan, 2005). Landfalling OND TCs tend to bring precipitation to, otherwise, climatologically drier regions of Luzon. These TCs also cause higher precipitation in a much wider area further to the north compared to the seasonal mean precipitation during OND. This increase in precipitation is more evident especially towards the eastern flanks of the Cordillera Central mountain range and the northern portion of the Sierra Madre mountain range (Figure 5e). Compared to JJAS TCs that tend to make landfall and track towards the northern region of Luzon (Figure 5c), OND TCs tend to make landfall near the central portion of Luzon and then continue to move westward (Figure 5f).

\subsection{2 | TC intensity and cyclogenesis locations}

Before evaluating extreme precipitation for each TC, we first look at the characteristics of TCs between JJAS and OND 1 day before landfall (or pre-landfall). We compared the pre-landfall movement speed between JJAS and OND TCs (Figure 6a) as well as the pre-landfall 
(a)

$$
\begin{gathered}
\text { Mean 2-day precipitation } \\
\text { June-September } \\
\text { (1978-2015, 2,319 samples) }
\end{gathered}
$$

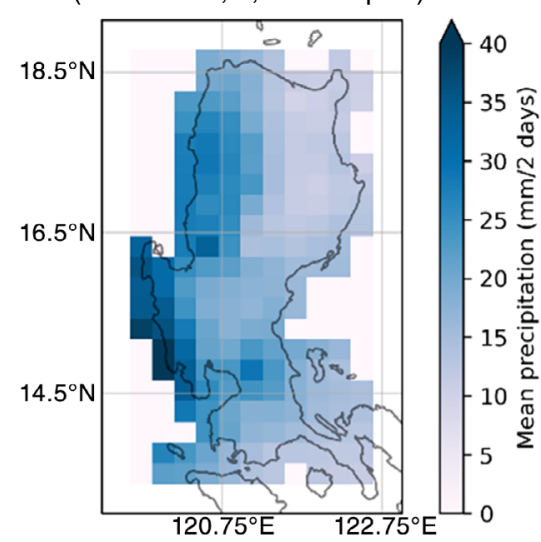

(d)

$$
\begin{aligned}
& \text { Mean 2-day precipitation } \\
& \text { October-December } \\
& \text { (1978-2015, 1,749 samples) }
\end{aligned}
$$

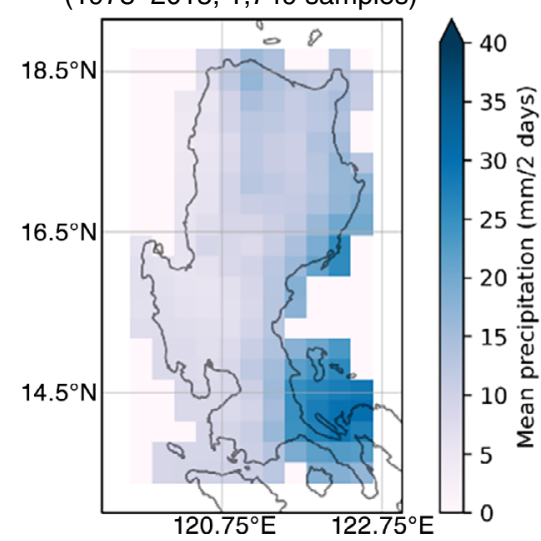

(b)

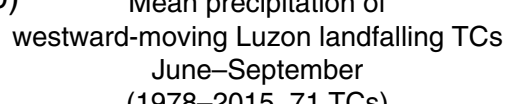

(1978-2015, 71 TCs)

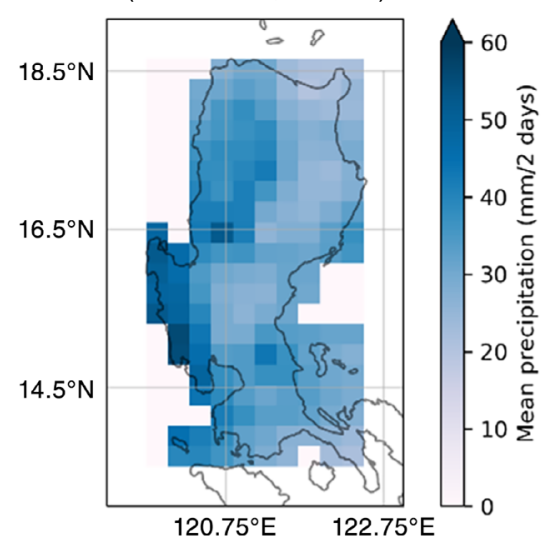

(e)

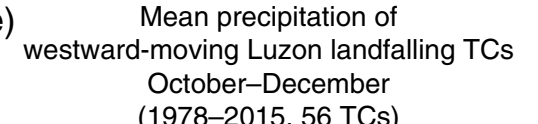

(1978-2015, 56 TCs)

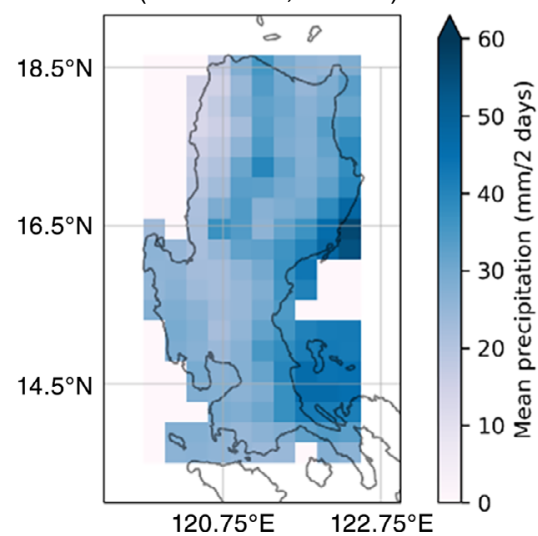

(c)
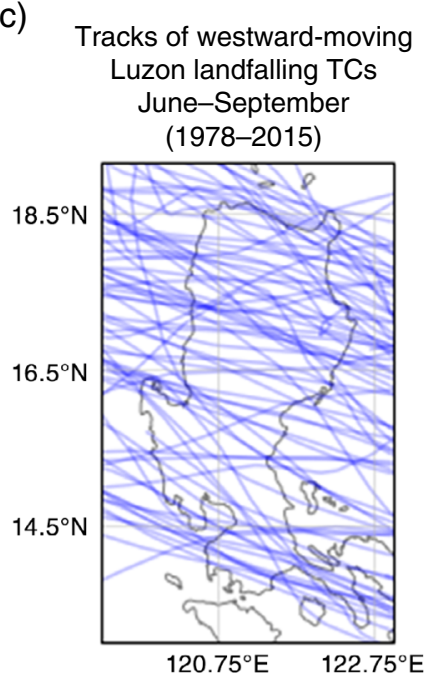

(f)

Tracks of westward-moving
Luzon landfalling TCs

October-November (1978-2015)

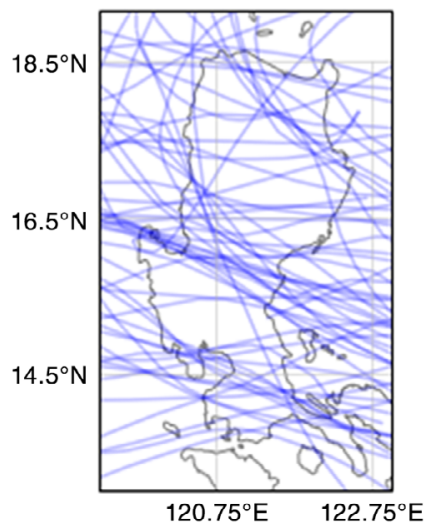

F I G U RE 5 The first row shows JJAS (a) seasonal mean 2-day precipitation, (b) 2-day mean precipitation for westward-moving Luzon landfalling TC and (c) TC tracks. The second row shows OND (d) seasonal mean 2-day precipitation, (e) 2-day mean precipitation for westward-moving Luzon landfalling TC and (f) TC tracks. Precipitation is calculated from APHRODITE with scales ranging from 0 to $40 \mathrm{~mm} / 2$ days for the seasonal means and from 0 to $60 \mathrm{~mm} / 2$ days for the landfalling TC precipitation means. TC tracks in lines are from IBTrACS [Colour figure can be viewed at wileyonlinelibrary.com]

intensity between the two seasons (Figure 6b) using a Kruskal-Wallis test (Kruskal and Wallis, 1952) at a significance level of $\alpha=.05$. There is no significant difference in the pre-landfall movement speed of TCs between JJAS and OND $(p=.62)$, while OND typically has TCs with higher pre-landfall intensities $(p<.001)$. The difference in TC intensities between the seasons is likely explained by the cyclogenesis locations of TCs, which may lead to more time for TC intensification. From all TCs in the region in JJAS (Figure 7a) and OND (Figure 7b), with a median cyclogenesis longitude of $135.45^{\circ} \mathrm{E}$, cyclones that make landfall in Luzon during JJAS (Figure 7c) tend to form nearer the coasts of the Philippines compared to those of in OND that form at a further median cyclogenesis longitude of $142.33^{\circ} \mathrm{E}$, towards the central portion of the WNP basin (Figure 7d). This is consistent with CorporalLodangco and Leslie (2016), in which TC formation clusters further to the southeast during winter due to the monsoon trough shifting further to the east and the western Pacific subtropical high extending further west towards the South China Sea (Chia and Ropelewski, 2002; Xiang et al., 2013). In addition, we found that TCs that have longer durations between cyclogenesis and landfall have higher intensities (Figure 8). Comparing the median time between cyclogenesis to landfall of TCs in JJAS and OND, the median time of OND TCs is significantly higher at $142.5 \mathrm{hr}$ compared to JJAS TCs with a median time of $117 \mathrm{hr}(p=.0059)$. As such, TCs that make landfall in Luzon in OND may be stronger, because they stay over the ocean longer, which allows for further cyclone intensification. 

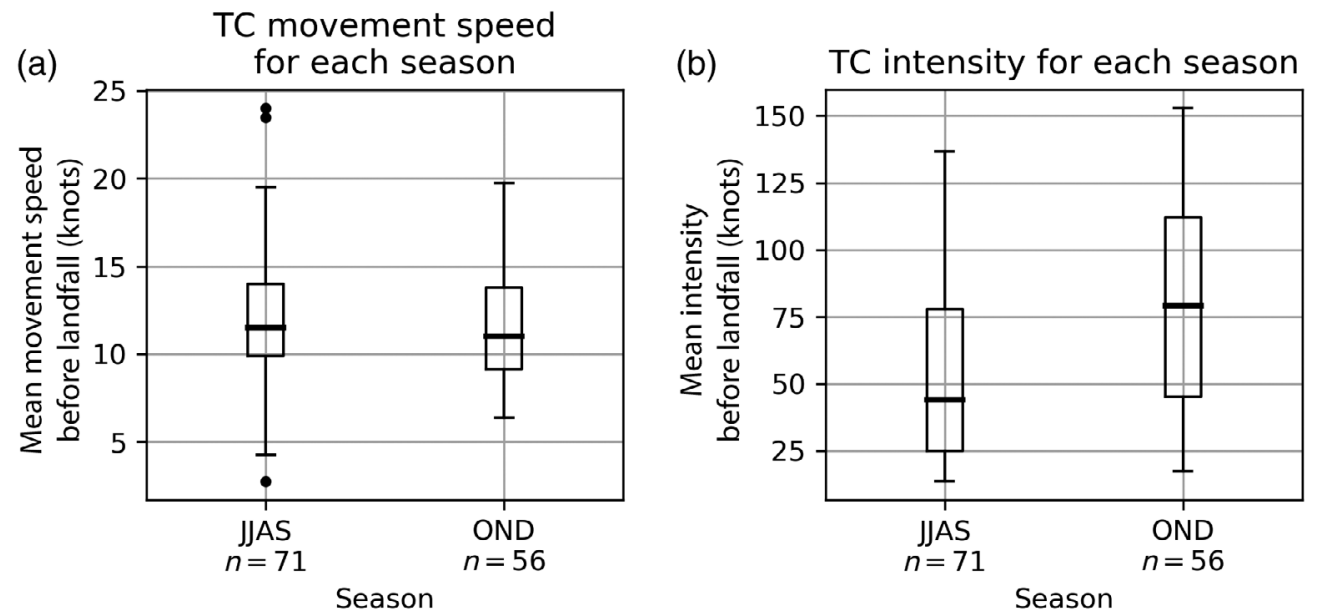

FI G URE 6 (a) 1-day mean TC movement speed before landfall for JJAS and OND and (b) 1-day mean TC intensity before landfall for JJAS and OND. These boxplots show the median (thick black line inside the box) and the interquartile range (IQR) at 25th percentile (Q1) and 75th percentile (Q3) (upper and lower boundaries of the box). The whiskers show the spread of the data, with lower whiskers showing the minimum, and upper whiskers showing the maximum calculated as $1.5 \times \mathrm{IQR}+\mathrm{Q} 3$. Any values beyond the upper whisker are plotted as outliers (black dots)

\section{Legend \\ I- $\mathrm{I}$ TC domain \\ Percentage of total TCs for the season

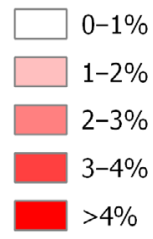

Percentage of total crossing TCs for the season

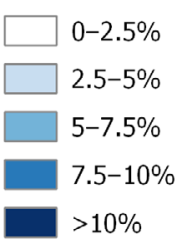

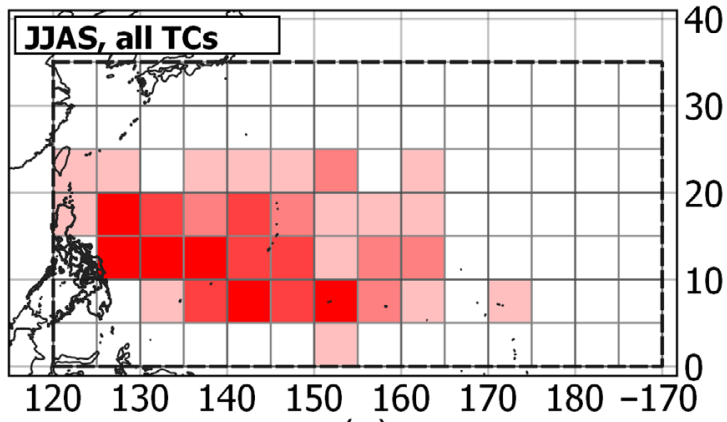

(a)

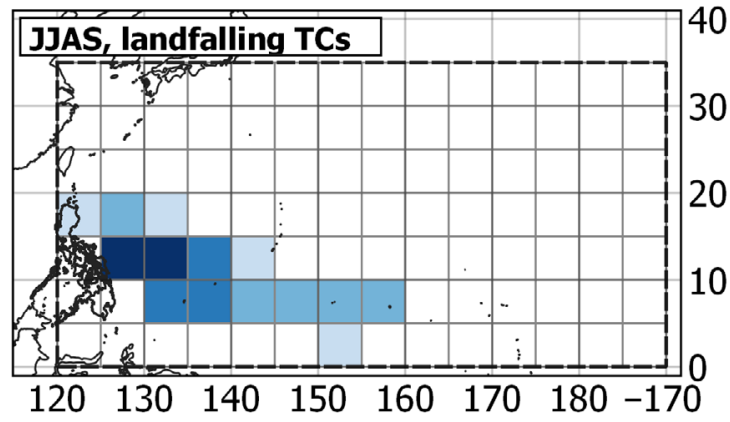

(c)

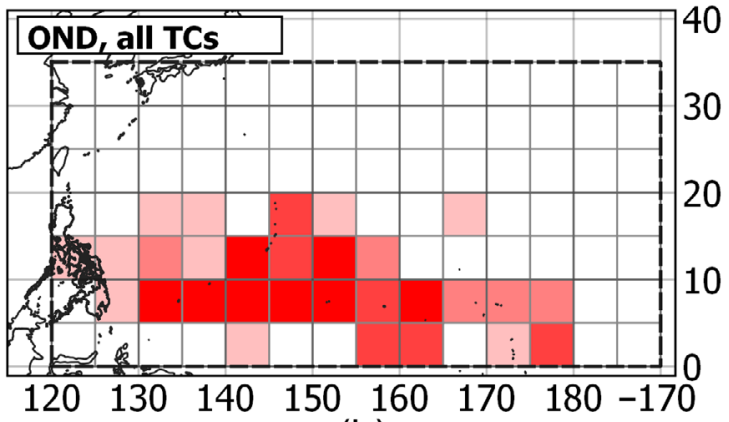

(b)

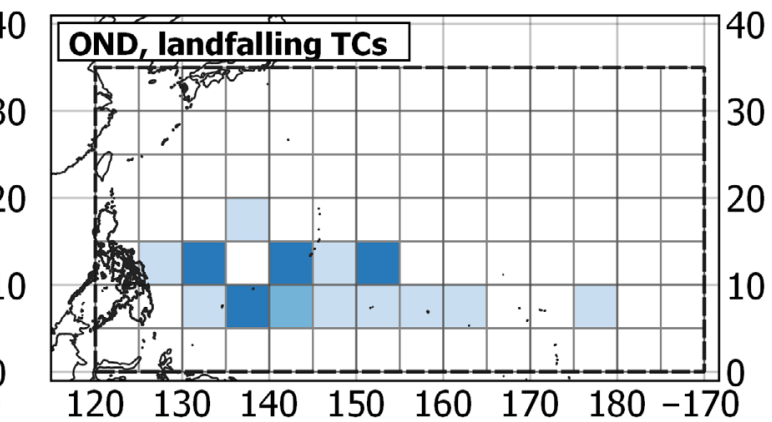

(d)

FI G U RE 7 The top row shows the density of TC cyclogenesis locations in the domain for (a) TCs in JJAS and (b) TCs in OND, as a percentage of all TCs in that season between 1978 and 2015. The bottom row shows the cyclogenesis densities for (c) TCs that make landfall in Luzon in JJAS and (d) TCs that make landfall in Luzon in OND, within the same period. The percentages are calculated by dividing the number of TCs that originate in each $5^{\circ} \times 5^{\circ}$ grid by the total number of TCs in the season (top row) and from the total number of TCs that make landfall (bottom row) [Colour figure can be viewed at wileyonlinelibrary.com]

\section{2 | TC characteristics compared to precipitation}

\subsection{1 | TC intensity and TC movement speed compared to mean precipitation and WPE}

We then examine the relationship between the mean precipitation across Luzon during the 2 days centred on landfall and the pre-landfall TC characteristics for all TCs. The one-day mean TC intensity compared to twoday mean precipitation is shown in Figure 9a while the comparison for the one-day mean TC movement speed is shown in Figure 9b. There is a significant $(p<.001)$, moderate positive relationship $(r=.37)$ between mean precipitation and TC intensity. There is also a very weak negative correlation $(r=-.14)$ between mean 


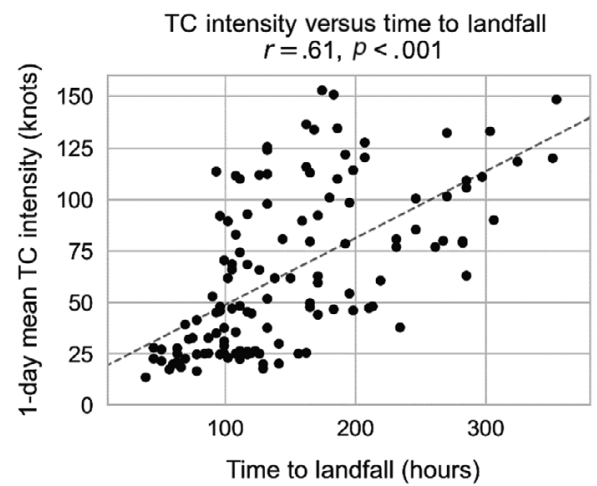

F I G U R E 8 TC intensity before landfall compared to time from TC cyclogenesis until landfall in Luzon. The dashed line shows the least-squares regression slope for each relationship. The Pearson correlation coefficient $(r)$ and $p$ value $(p)$ are listed above each plot

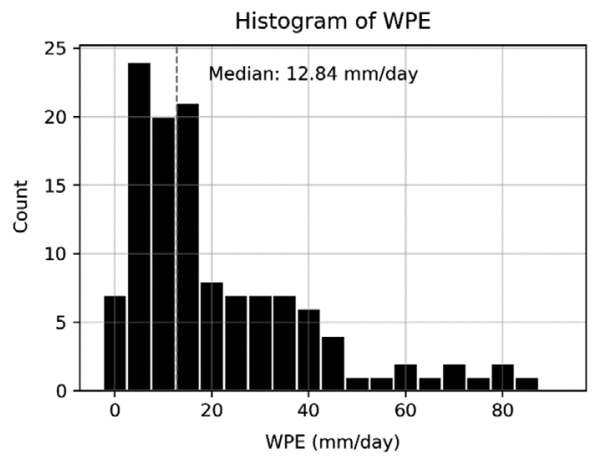

FI G URE 10 The histogram of WPE for all TC cases. The leftmost bin includes only zero WPE values, and the dashed line shows the median WPE of $12.84 \mathrm{~mm} / 2$ days (a) Mean precipitation versus TC intensity $r=.37, p<.001$

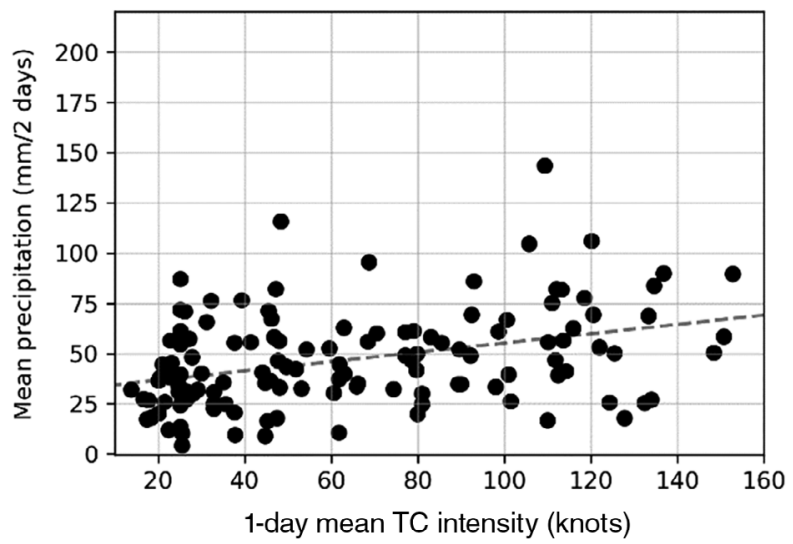

(b) Mean precipitation versus TC movement speed

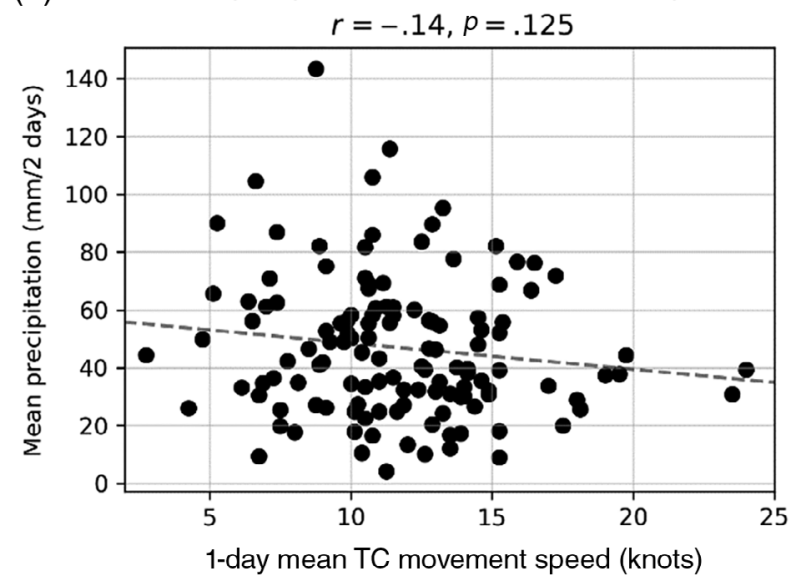

F I G URE 9 Similar to Figure 8 but for mean precipitation 1-day after landfall versus (a) 1-day mean TC intensity before landfall and (b) 1-day mean TC movement speed before landfall, for 127 TCs that made landfall in Luzon between 1978 and 2015

precipitation and TC movement speed $(p=.125)$. These show that TCs that are strong before landfall may produce more mean rainfall than weaker TCs, while there is not sufficient evidence to conclude that the movement speed of TCs before landfall has a linear relationship with mean precipitation after landfall.

Figure 10 shows the distribution of WPE for all TC cases included in this study. The median WPE of all the $127 \mathrm{TCs}$ is $12.84 \mathrm{~mm} / 2$ days, while the mean is $23.24 \mathrm{~mm} / 2$ days. Although the distribution is positively skewed, most TCs that make landfall in Luzon (94.49\%) have a non-zero WPE. Thus, many of the TCs produce extreme rainfall, as the TC-associated precipitation exceeds the 95th percentile threshold for at least one grid point in Luzon.

Next, we compare WPE against pre-landfall TC intensity (measured by wind speed) in Figure 11a and prelandfall movement speed in Figure 11b. While stronger TC winds do not necessarily cause stronger precipitation, at $\alpha=.05$, WPE has a significant moderate positive relationship with intensity $(r=.32$ and $p<.001)$ and a nonsignificant weak negative correlation with movement speed ( $r=-.14$ and $p=.059)$. Fitting a logarithmic relationship (not shown) between WPE and movement speed also does not yield significant results $(r=-.14$ and $p=.26)$. This shows that stronger TCs may pose additional risks due to a combination of stronger winds and higher amounts of precipitation. However, as the relationships are not especially strong and there is clearly a substantial amount of inter-storm WPE variance that is not explained by either intensity or movement speed, we decided to group TCs in categories to show likelihood of higher WPE. While this may not explain the variance, this allows us to compare inter-storm WPE between conveniently identifiable categories in a more probabilistic manner. These categories will be discussed in the next subsection. 
(a)

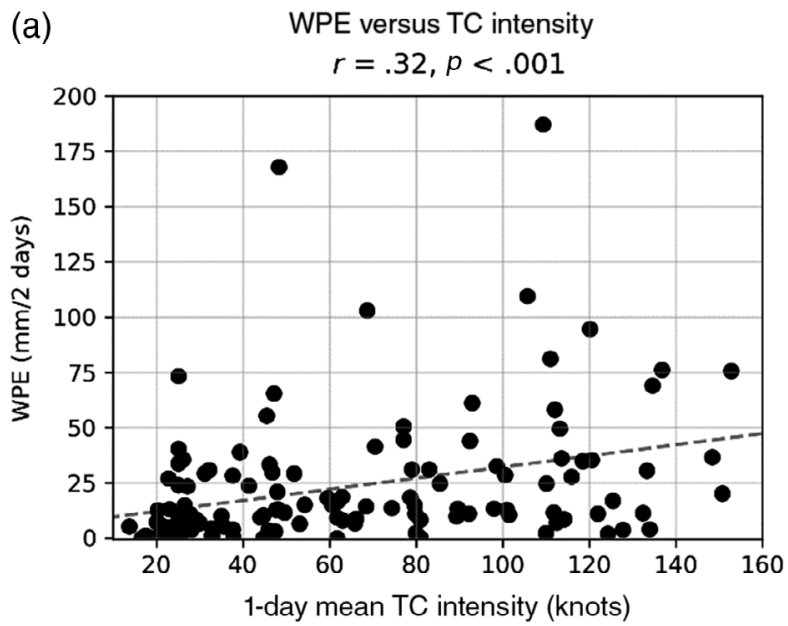

(b)

WPE versus TC movement speed

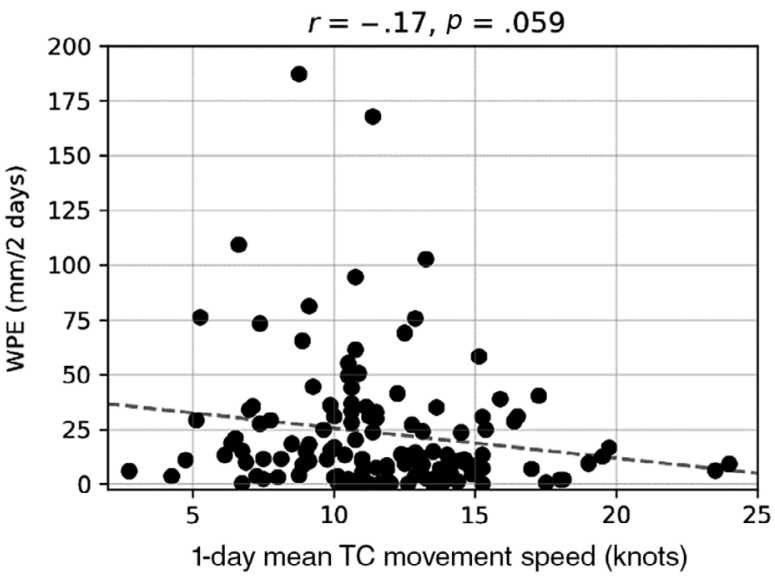

F I G U RE 11 Similar to Figure 8 but for WPE 2 days centred on landfall versus (a) 1-day mean TC intensity before landfall and (b) 1-day mean TC movement speed before landfall

T A B L E 1 Total counts of TCs for the three different categorisations

\begin{tabular}{|c|c|c|}
\hline \multicolumn{3}{|c|}{ Intensity classification } \\
\hline Category & $\begin{array}{l}\text { Intensity (1-min maximum } \\
\text { sustained wind) }\end{array}$ & $\begin{array}{l}\text { Total } \\
\text { TCs }\end{array}$ \\
\hline Non-TY & $<64$ knots & 72 \\
\hline TY & $\geq 64$ knots & 55 \\
\hline \multicolumn{3}{|c|}{ Movement speed classification } \\
\hline Category & Movement speed & Total TCs \\
\hline Slow & $<11.38$ knots & 63 \\
\hline Fast & $\geq 11.38$ knots & 64 \\
\hline \multicolumn{3}{|c|}{ Season classification } \\
\hline \multicolumn{2}{|c|}{ Seasonal category } & Total TCs \\
\hline \multicolumn{2}{|l|}{ JJAS } & 71 \\
\hline \multicolumn{2}{|l|}{ OND } & 56 \\
\hline
\end{tabular}

Note: The intensity categorisation is based on a threshold of 64 knots to separate non-TYs and TYs. TCs are also categorized according to movement speed based on the median of 11.38 knots and, finally, according to season.

\subsection{2 | TC characteristics categories compared to WPE}

Table 1 shows the TC counts for the different categorisations. From all landfalling westward-moving TCs in Luzon, 72 (or $57 \%$ of TCs) are non-Typhoons (non-TY), and 55 (or 43\%) are Typhoons (TY). This is consistent with the results of Cinco et al. (2016) where they report that more non-TYs than TYs make landfall. We used the median pre-landfall movement speed of TCs of 11.38 knots to categorize TCs as slow or fast. Finally, while there are more TCs in JJAS (71) than in OND (56), their monthly frequencies are similar at 17.75 and 18.67 TCs per month, respectively.

For all following comparisons between categories, Kruskal-Wallis tests were conducted to test the difference between the median of the populations at a significance level of $\alpha=.05$. Figure 12a,b shows boxplots that compare WPE between TC movement speed and intensity categories, while Figure 12c compares WPE between seasons. Figure 13, on the other hand, shows boxplots that compare WPE for combined categories, particularly for intensity and movement speed (Figure 13a), season and intensity (Figure 13b) and season and movement speed (Figure 13c).

From Figure 12a, slow TCs yield higher WPE compared to fast TCs $(p=.017)$, while Figure $12 \mathrm{~b}$ shows that TYs yield higher WPE compared to non-TYs $(p<.001)$. Upon combining the intensity and movement speed categories in Figure 13a, no significant differences in WPE were found between fast TYs and slow TYs, or between fast non-TYs and slow non-TYs. On the other hand, Figure 13a shows that slow TYs yield higher WPE compared to slow non-TYs $(p=.01)$, while fast TYs similarly yield higher WPE compared to fast non-TYs $(p=.003)$. Simply put, for similar movement speed, stronger TCs cause more extreme precipitation. However, when TCs are of similar intensity categories, extreme precipitation tends to be similar between TCs of different movement speed categories. This means that TC intensity is more influential in determining extreme precipitation than TC movement speed.

Figure 12c shows that at $\alpha=.05$, no significant difference was found between the WPE of JJAS and OND TCs. When categorized by both season and intensity (Figure 13b), there is also no significant difference between JJAS TYs and OND TYs, or between JJAS non- 
(a)

APHRODITE 2-day WPE for each speed category

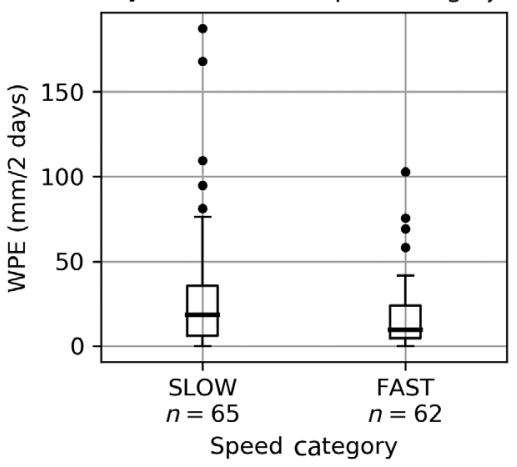

(b)

APHRODITE

2-day WPE for each intensity category

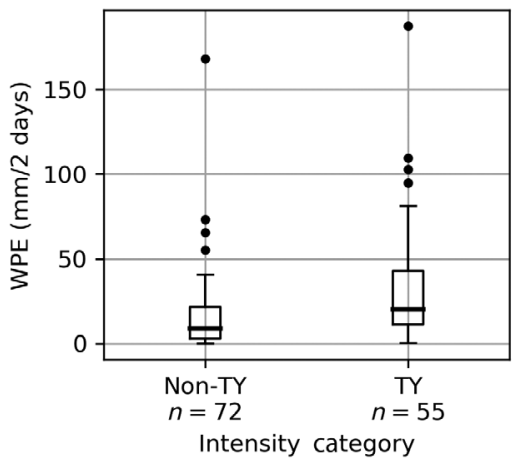

(c)

(c) APHRODITE 2-day WPE for each season

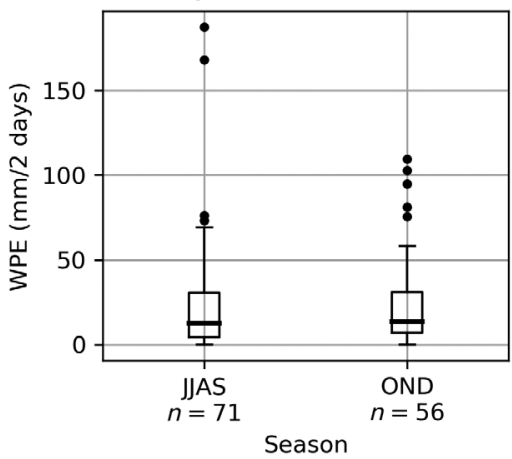

F I G U RE 12 Boxplots similar to Figure 6 but for comparing WPE between (a) slow and fast TCs, (b) non-TYs and TYs and (c) for TCs in JJAS and OND
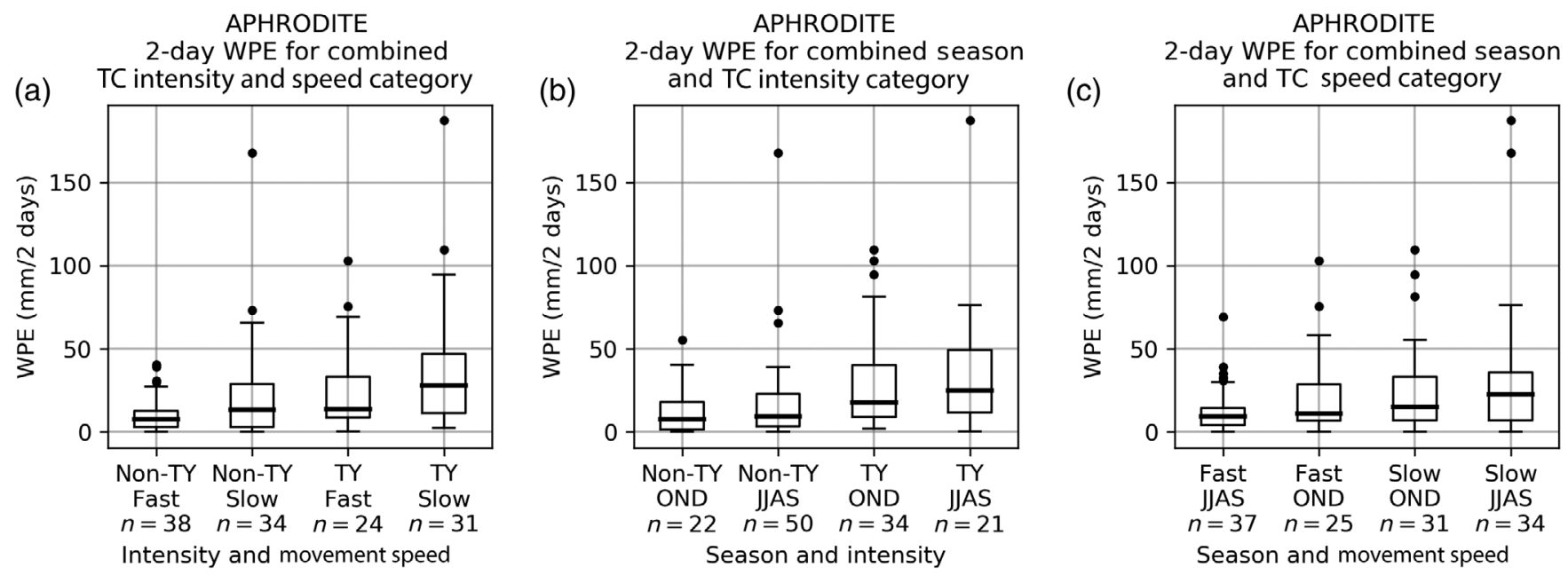

F I G U R E 13 Boxplots similar to Figure 6 but for comparing WPE between (a) the combined intensity and movement speed categories, (b) the combined season and intensity categories and (c) for the combined season and movement speed categories

TYs and OND non-TYs. However, JJAS TYs yield higher WPE than JJAS non-TYs $(p=.001)$ while OND TYs similarly yield higher WPE than OND non-TYs $(p=.007)$. In terms of combined season and movement speed categories, when considering similar seasons, JJAS slow TCs have higher WPE than JJAS fast TCs, while there is no significant difference between fast and slow TCs during OND (Figure 13c). From these results, we can see that within the same season, stronger TCs (TYs) cause higher precipitation, while movement speed only tends to cause higher WPE during the JJAS season. As such, when considering TCs in the same season, TC intensity is again more important than movement speed in determining extreme precipitation.

The above analysis suggests that for either TCs of similar movement speed or TCs within the same season, stronger TCs cause more extreme precipitation. However, from Figure 6a,b, respectively, it was previously observed that while TC movement speeds are similar between the two seasons, OND TCs tend to be stronger than that of JJAS TCs $(p<.001)$. This raises the apparent contradiction of why OND TCs, which are typically more intense than JJAS TCs (Figure 6b), have similar WPE to JJAS TCs (Figure 12c). To address this, we conduct a decision table analysis that will be discussed in the following section.

\subsection{3 | WPE decision table analysis}

At first glance, it seems counterintuitive that while strong TCs yield higher WPE than weak TCs, and there is a higher number of strong TCs in OND than JJAS, the WPE of OND TCs is not statistically different from that 
TA B LE 2 Decision table for combined categories of season, intensity and movement speed

\begin{tabular}{lllllll} 
Season & Intensity & $\begin{array}{l}\text { Movement } \\
\text { speed }\end{array}$ & $\begin{array}{l}\text { Mean WPE } \\
\left(\mathbf{m m ~ d a y ~}^{-1}\right)\end{array}$ & Count & $\begin{array}{l}\text { TCs that exceed median } \\
\text { WPE of all TCs }\end{array}$ & $\begin{array}{l}\text { Probability to exceed median } \\
\text { WPE of all TCs }\end{array}$ \\
\hline JJAS & Non-TY & Fast & 17.87 & 26 & 6 & $23.08 \%$ \\
& & Slow & 19.73 & 24 & 14 & $58.33 \%$ \\
& TY & Fast & 22.15 & 11 & 7 & $63.64 \%$ \\
& & Slow & 56.32 & 10 & 8 & $80.00 \%$ \\
OND & Non-TY & Fast & 13.63 & 12 & 4 & $33.33 \%$ \\
& & Slow & 17.07 & 10 & 4 & $40.00 \%$ \\
& \multirow{2}{*}{ TY } & Fast & 30.13 & 13 & 8 & $61.54 \%$ \\
& & Slow & 30.49 & 21 & 13 & $61.90 \%$
\end{tabular}

Note: The mean WPE for each category is shown in the fourth column. The fractional counts of TCs for each category that exceed the median WPE of all TCs are calculated as probabilities and are listed in the seventh column.

of JJAS TCs. To resolve this apparent contradiction, a decision table was formed to examine how the combination of all categories (season, intensity and movement speed) is related to WPE. Table 2 shows the different categories (season, intensity and movement speed) in the first three columns, along with the mean WPE and the total number of TCs per category in the fourth and fifth columns. We then compared the distribution of WPE for TCs in each category to the median WPE of all TCs of $5.90 \mathrm{~mm} \mathrm{day}^{-1}$ (sixth column) to determine the percentage of TCs in each category that exceed the median WPE (seventh column).

Based on Table 2, OND has a higher fraction of TYs (60.71\%) compared to JJAS (29.58\%). In both seasonal categories, TYs, in general, have higher chances of exceeding the median WPE compared to non-TYs. Between seasons, JJAS TCs tend to have higher mean WPE and are also more likely to exceed the median WPE of all TCs compared to most OND TCs in the same intensity and movement speed categories. However, there are a few exceptions: the OND TY Fast category has a higher mean WPE (30.13 mm/2 days) compared to the JJAS TY fast category ( $22.15 \mathrm{~mm} / 2$ days), while the OND non-TY fast category has a higher probability to exceed the median WPE (33.33\%) compared to the JJAS non-TY fast category $(23.08 \%)$. Besides the mentioned exceptions, most of these means and probabilities between categories show that while intensity and movement speed matter for anticipating higher WPE, this relationship is stronger for most JJAS TCs than for OND TCs. We hypothesize that this is due to higher precipitation rates overall in the JJAS season due to the source and amount of moisturethe warm and moist southwesterly monsoonal flow (Bagtasa, 2017) during JJAS, compared to the lower moisture north-easterly flow in the WNP during OND (Ding and Chan, 2005; Guo et al., 2017).

\subsubsection{WPE comparison and decision table using $\mathrm{TRMM}_{3 \mathrm{hr}}$ data}

The above analyses, particularly the comparisons between categories with WPE as well as the decision table, were also conducted using the $\mathrm{TRMM}_{3 \mathrm{hr}}$ dataset. While it is true that there are fewer TCs that we can include in the analysis due to the shorter time-period involved, using a higher temporal resolution dataset eliminates the need for assuming a uniform distribution of precipitation throughout the day as was done in the $\mathrm{APHRO}_{\text {uniform }}$ dataset. Furthermore, while there are still differences between the datasets, using WPE as a metric works fairly well in terms of eliminating a systematic difference in the means between these datasets.

Figure S3b,c shows that results remained the same for the WPE comparison between the intensity and season categories separately: TYs yield higher WPE than nonTYs, while there is no significant difference between the WPE of JJAS and OND TCs. When comparing WPE for combined intensity and season categories, results remained similar between $\mathrm{TRMM}_{3 \mathrm{hr}}$ and $\mathrm{APHRO}$ uniform. Figure S4a shows that TYs continue to cause higher median WPE than non-TYs in both the JJAS $(p=.03)$ and OND $(p=.08)$ seasons. Likewise, from Figure S4b, we see that when TC intensity is similar, there is no significant difference in the WPE between the TCs in the JJAS and OND seasons.

The differences between $\mathrm{TRMM}_{3 \mathrm{hr}}$ and $\mathrm{APHRO}_{\text {uniform }}$ arise when considering TC movement speeds in comparing WPE between categories. In contrast to our previous results using $\mathrm{APHRO}_{\text {uniform }}$, there is no significant difference between the WPE of fast and slow TCs in TRMM ${ }_{3 \mathrm{hr}}$ (Figure S3a). From Figure S4a, while WPE continues to be higher for slow TYs compared to slow non-TYs $(p<.001)$ and there continues to be no significant 
difference between fast non-TY and slow non-TY, there is no significant difference between the fast TY and fast non-TY categories. Slow TYs now yield higher WPE than fast TYs $(p=.029)$ when using TRMM $_{3 \mathrm{hr}}$ in our calculations.

Comparing the decision tables between $\mathrm{APHRO}_{\text {uniform }}$ (Table 2) and TRMM $\mathrm{Thr}_{3 \mathrm{hr}}$ (Table S1), JJAS TCs continue to mostly have higher probabilities to exceed the median WPE for their respective datasets. One exception is the JJAS non-TY slow category that has a lower probability of exceeding the median WPE (18.18\%) compared to the OND non-TY slow TC category (25.00\%). However, it should be noted that since there are fewer TCs included in $\mathrm{TRMM}_{3 \mathrm{hr}}$, any small difference in the number of TCs for each category that exceed the median WPE of all TCs can greatly affect their probabilities and relationships.

\section{4 | DISCUSSION}

All TCs included in this study originate in the WNP (Figure 7) before tracking west and making landfall in Luzon. At the beginning of the southwest monsoon season in June, the number of landfalling TCs in Luzon increases, peaking by July, and then decreases towards the end of the monsoon season in September (Figure 2). The number of landfalling TCs in Luzon increases again by the start of the northeast monsoon season in October and then tapers off by December. According to Cinco et al. (2016), more TCs cross or form within the Philippine Area of Responsibility (a region of TC monitoring used by forecasters in the Philippines) in JJAS than OND. However, the ratio of TCs that make landfall in Luzon compared to the total TCs that make landfall in the Philippines is higher in OND (37\%) than in JJAS (27\%). As landfalling TCs cause significant damages due to strong winds and high amounts of precipitation (Camargo and Hsiang, 2015), the higher likelihood of TCs making landfall in Luzon in OND also means higher disaster risk during the season.

As mentioned in Section 3.1.2, one possible reason for the higher ratio of TC landfalls in Luzon compared to landfalls in the Philippines during OND is the combination of the retraction of the monsoon trough towards the east, as well as the extension of the western Pacific subtropical high towards the west. The monsoon trough is part of the intertropical convergence zone that increases the chance of TC formation (Gray, 1977). Regarding TC movement direction, Bagtasa (2017) hypothesizes that the western Pacific subtropical high acts as a steering ridge causing a more southerly and westward movement of TCs during the months of September-December. We hypothesize that the combination of TCs forming further east along with a more southerly and westward movement of TCs in the season may cause higher ratios of TC making landfall in Luzon during OND.

TCs in OND are typically stronger if they do make landfall (Figure 6b). We hypothesize that one possible factor why landfalling OND TCs are more intense is due to these TCs forming further to the east (Figure 7d) allowing for a TC to further intensify as it spends more time over the ocean before making landfall in Luzon (Figure 8). In terms of precipitation, it is seemingly counterintuitive that while stronger TCs yield higher WPE, the WPE of typically stronger OND TCs is similar to that of typically weaker JJAS TCs. However, upon comparing the likelihood of higher WPE between the seasons through a decision table, compared to OND, JJAS TCs have higher chances of exceeding the median WPE of all TCs regardless of intensity. This suggests that while intensity is important in anticipating higher WPE, this relationship is stronger for JJAS TCs than OND TCs. We hypothesize that this is due to an environment with higher moisture during JJAS and, thus, higher amounts of precipitation during a TC event. This is especially true if the TC interacts with the southwest monsoon, enhancing precipitation in the southwestern regions of Luzon in the process (Cayanan et al., 2011; Bagtasa, 2019).

Precipitation during TC days in JJAS is similar in spatial pattern to, but stronger than, the mean daily precipitation. Figure 5b shows that during days with landfalling TCs in Luzon, rainfall is mostly distributed towards the western regions of Luzon towards the western flank of the Cordillera Central mountain range and southwestern section of the Zambales mountain range. As previously mentioned, this is due to the moisture source in JJAS from the warmer and moister southwesterly winds during the season (Xiang et al., 2013) where additional and higher rainfall is observed towards the western region of Luzon during TC-landfall days (Bagtasa, 2020). As TCs tend to move towards the north during JJAS, they bring more precipitation to the southwestern regions of Luzon, causing extreme precipitation in the process.

On the other hand, landfalling TCs in OND tend to move towards the central and southern regions of Luzon, while precipitation is distributed in regions that, otherwise, experience comparatively less extreme precipitation for the season. This is more apparent particularly towards the eastern flanks of the Cordillera Central mountain range and the northern portion of the Sierra Madre mountain range (Figure 5e). This may pose problems for crops, particularly rice, that are planted in Luzon during the prior months of October-December and then grown between the dry season of January-June (Koide et al., 2013). Abnormally high precipitation and strong 
winds during extreme weather conditions such as TCs hamper growth of rice crops, thus reducing yield (Lansigan et al., 2000).

Based on our results, the season, intensity and then finally the movement speed 1 day prior can help to anticipate the associated extreme precipitation of landfalling TCs. While TC movement speed is important, TC intensity along with season can be more useful to estimate the WPE of TCs. Understanding the implications when which season a TC forms and makes landfall can be helpful in estimating both the likelihood of extreme precipitation as well as its spatial distribution. TCs making landfall in JJAS have higher likelihoods causing more extreme precipitation, while TCs making landfall in OND distributes precipitation in other regions. The decision table (Table 2) can be used as reference to help anticipate the probability of extreme precipitation caused by westward-moving TCs expected to make landfall in Luzon. However, we recommend that our results be considered as a preliminary tool, to be used together with quantitative precipitation forecasts from NWP models. The application of our results to prediction also requires verification in an operational setting. Other TC characteristics, such as radius, landfall location and movement direction, may also be related to extreme precipitation, which unfortunately were not explored in this study. This study also does not consider TCs that make landfall from other directions, and we also did not examine the extreme precipitation of TCs that recurve instead of making landfall. As such, in future studies, we may also consider TC landfall location, direction as well as the distance between TC and land in estimating extreme precipitation as well as taking a further look at their spatial distribution.

One limitation of this study is data availability, both for TC characteristics and precipitation. Only TCs between 1978 and 2015 were considered, as TC intensity data are very limited in the pre-satellite era (Knapp et al., 2010; Knutson et al., 2010), and the APHRODITE record ends in 2015. While APHRODITE has been used in previous precipitation studies in the Philippines, these data are approximated from the available weather stations through an interpolation method (Yatagai et al., 2012). While it is a comprehensive dataset, it is still limited by the availability and quality of weather observations in the country (see Akasaka et al., 2007 for the locations of these stations). Finally, APHRODITE only has daily accumulations. As such, it is possible that our estimates of 24-hr precipitation accumulation after landfall may be biased by the lack of sub-daily information.

Satellite-based precipitation products such as TRMM, CMORPH and the Global Precipitation Measurement (GPM) mission by National Aeronautics and Space
Administration are also available and could be used for TC precipitation studies. While these products offer higher spatial and temporal resolution precipitation estimates, they are available only in more recent years (TRMM from 1998 to 2019, CMORPH from 2002 to present and GPM from 2000 to present). Using these satellite products would reduce the sample size of TCs, potentially making the relationships between TC characteristics and extreme precipitation less apparent. According to Jamandre and Narisma (2013), when compared with observations from weather stations, satellite products such as TRMM and CMORPH perform well in estimating daily precipitation in eastern Luzon during rainfall events where precipitation is greater than a threshold of $100 \mathrm{~mm}$. However, they have also noted that measurements below this threshold tend overestimate precipitation. This may have an impact in estimating rainfall amounts during TCs with lower amounts of precipitation. Another possible issue that may arise is the technical differences between these satellites as well as their different precipitation estimation algorithms, which may lead to discrepancies between measurements especially if we were to use measurements from different satellites along with gridded precipitation datasets through different years.

Despite the limited number of TCs during the available period of $\mathrm{TRMM}_{3 \mathrm{hr}}$, we included analysis of the higher temporal resolution dataset in our calculations for this study to provide an additional line of evidence. While there are key differences in the results between $\mathrm{APHRO}_{\text {uniform }} \mathrm{TRMM}_{3 \mathrm{hr}}$ that we cannot ignore, our primary findings, particularly for TC intensity and season, remain consistent between the two datasets. TC intensity and season continue to be more important in determining extreme precipitation than movement speed. It should be noted, however, that the lower sample size of TCs in $\mathrm{TRMM}_{3 \mathrm{hr}}$ reduces the robustness of the relationships between the different categories as well as the probabilities in our decision tables. As data become available and more TCs may continue to make landfall in Luzon, in future studies, we may consider a combined approach to evaluate extreme TC precipitation using estimates derived from rain gauges, satellites and modelling as demonstrated by Kim et al. (2019).

Another limitation of this study is the time scales involved in using WPE as a measure of extreme precipitation. As WPE is limited in measuring TC precipitation for $48 \mathrm{hr}$ centred on TC landfall, it is very likely that the total precipitation throughout a TCs lifetime is not included in our measurements. However, using WPE as an index of extreme rainfall ensures that we have a consistent method of comparing landfalling TCs at their point of immediate impact during the 48 -hr period centred on 
landfall. This measurement may be useful for anticipating rapid onset hazards, which may arise during TC landfall such as urban flooding, flash flooding and landslides. Comparing TC characteristics with the total precipitation of all TCs affecting the Philippines (both landfalling and non-landfalling) throughout their lifetimes may be considered in a future study.

\section{5 | CONCLUSIONS}

This study was motivated by the need to quantify the relationships between TC characteristics (such as intensity, movement speed and season) and TC precipitation. Previous TC precipitation studies in the Philippines typically focus on the interaction of TCs with the southwest monsoon and its effects on precipitation while others analyse case studies on the effect of topography on TC rainfall. To the best of our knowledge, there are no studies that compare characteristics of westward-moving TCs that make landfall in Luzon with precipitation. Relationships established in this study can be used in conjunction with NWP forecasts during TC events to augment precipitation estimates for TCs that are expected to make landfall.

Using gridded precipitation data from APHRODITE and TRMM (conclusions below are mainly for APHRODITE because of the larger TC sample size, though a few differences seen in TRMM are noted) along with the TC characteristics from IBTrACS, we evaluated the precipitation of westward-moving TCs that make landfall in Luzon. The spatial distribution of the mean daily precipitation of a total of 127 TCs was first compared to the mean daily precipitation per season. During JJAS, the precipitation during TC days is higher than, but similar in spatial pattern to the mean daily precipitation: precipitation is mostly distributed towards western Luzon at the western flank of the Cordillera Central mountain range and southwestern section of the Zambales mountain range. In contrast, OND TCs tend to move towards the central and southern regions of Luzon after making landfall, so their precipitation is distributed in regions of Luzon that otherwise experience less precipitation.

We then introduced the Weighted Precipitation Exceedance, or WPE as a measure of extreme precipitation that considers both the magnitude and spatial extent of the extreme TC-associated precipitation, by adapting the methods of Diffenbaugh et al. (2005), Guo et al. (2017) and Kim et al. (2019). WPE is the area mean of TC precipitation that exceeds the local 95th percentile of precipitation, with grid cells that do not exceed this threshold set to zero, for a given time window (here, we have used $48 \mathrm{hr}$ centred on landfall). We examined the relationship between WPE and TC intensity, movement speed and season (JJAS compared to OND). WPE moderately increases as pre-landfall TC intensity increases. TCs were then categorized according to pre-landfall strength, pre-landfall movement speed and season to determine the likelihood of extreme precipitation for conveniently identifiable categories, both individual and combined.

Typhoons or TYs (TCs with 1-min maximum sustained wind speed $\geq 64$ knots before landfall) cause higher WPE than non-Typhoons (non-TYs), while slow TCs (movement speed $<11.38$ knots) yield higher WPE than fast TCs (movement speed $>11.38$ knots before landfall). When considering TCs of similar intensity, there are no significant differences in WPE between fast TYs and slow TYs or between fast non-TYs and slow non-TYs. For TCs of similar movement speed, slow TYs yield higher WPE than slow non-TYs, and fast TYs yield higher WPE than fast non-TYs. On a similar note, TYs yield higher WPE compared to non-TYs within the same season (JJAS or OND). These relationships suggest that WPE has a stronger relationship with pre-landfall TC intensity than with pre-landfall TC movement speed or season. When performing the same analysis on $\mathrm{TRMM}_{3 \mathrm{hr}}$-a higher temporal resolution dataset with a smaller sample size-most results continue to be consistent except for subcategories involving movement speed. For $\mathrm{TRMM}_{3 \mathrm{hr}}$, there is no significant difference between the WPE of fast and slow TCs, and fast non-TYs and slow non-TYs while slow TYs yield higher WPE than fast TYs $(p=.029)$.

In this study, we raised a few hypotheses to explain differences between TCs of the JJAS and OND seasons. First, we hypothesized that there is a higher ratio of TCs making landfall in OND due to a combination of the shifting of the monsoon troughs from south to east along with the western Pacific subtropical high extending further towards the South China Sea. While the monsoon trough causes TCs to form further away towards the east, the western Pacific subtropical high may cause TCs to have a more southerly and westward movement. The combination of these two factors may then cause higher TC landfalls in Luzon during OND. We also hypothesized that OND TCs are stronger, because they have a longer time to develop before making landfall. Besides the cyclogenesis location and intensity of OND TCs, we have also hypothesized that JJAS TCs, for a given intensity, cause more rainfall, because there is more moisture available to them. However, validating these hypotheses is not within the scope of this study. These may be explored in further studies to explain the climatology and characteristics of TCs that make landfall in Luzon.

Our results may aid in forecasts in the Philippines particularly for disaster risk reduction and mitigation 
efforts. As disaster risk is a function of hazard, exposure and vulnerability (Bonapace et al., 2012), results of this study show that risk for westward-moving TCs making landfall in Luzon varies between the seasons due to the different exposed regions as well as the different magnitudes of the rainfall hazards involved. During JJAS, disaster risk is aggravated when TCs make landfall in Luzon due to the generally higher amounts of precipitation involved as well as higher chances of extreme precipitation, especially towards the southwestern regions. During OND, however, besides bringing precipitation to, otherwise, drier areas of Luzon for the season towards the central and northeastern regions, TCs are generally stronger and may cause more wind damage. It is then important for forecasters and disaster risk reduction managers to consider the season, intensity and movement speed of possible landfalling TCs when anticipating their possible impacts.

\section{ACKNOWLEDGEMENTS}

The authors would like to thank the anonymous reviewers for their valuable comments that helped improve the quality of the paper. They also thank Dr. Xiangbo Feng for the insightful discussions during the revision process. Bernard Alan B. Racoma is supported by a scholarship under the Commission on Higher Education of the Philippines' Joint Development of Niche Programmes agreement with the British Council. Bernard Alan B. Racoma would also like to thank University of Reading and University of the Philippines, Diliman, for the institutional support. Nicholas P. Klingaman was funded by an Independent Research Fellowship from the Natural Environment Research Council and by the National Centre for Atmospheric Science Atmospheric Hazards in Development Countries: Risk Assessment and Early Warning (ACREW) programme. Reinhard K. H. Schiemann is supported by the National Centre for Atmospheric Science. APHRODITE data are jointly provided by Hirosaki University, Kyoto University and Chiba University and are available from at http://aphrodite.st.hirosaki-u.ac.jp/. IBTrACS data are available from the National Climatic Data Centre at https://www.ncdc.noaa.gov/ibtracs. The TRMM 3B42 V7 three-hourly rain-rate data were provided by the NASA/ Goddard Space Flight Centre's Precipitation Measurement Missions Science team and PPS, which develop and compute the TRMM 3B42 V7 three-hourly rain rate as a contribution to project TRMM, and archived at the NASA GES DISC.

\section{AUTHOR CONTRIBUTIONS}

Bernard Alan Baluyut Racoma: Conceptualization; data curation; formal analysis; investigation; methodology; software; validation; visualization; writing - original draft; writing - review and editing. Nicholas P. Klingaman: Methodology; resources; supervision; writing - original draft; writing - review and editing. C Holloway: Methodology; supervision; writing - original draft; writing - review and editing. Reinhard Schiemann: Methodology; supervision; writing - original draft; writing - review and editing. G Bagtasa: Methodology; resources; supervision; writing - original draft; writing - review and editing.

\section{ORCID}

Bernard Alan B. Racoma (D) https://orcid.org/0000-00027778-7273

Nicholas P. Klingaman (1) https://orcid.org/0000-00022927-9303

Christopher E. Holloway (1) https://orcid.org/0000-00019903-8989

Reinhard K. H. Schiemann (1) https://orcid.org/0000-00033095-9856

Gerry Bagtasa (1) https://orcid.org/0000-0002-5433-7122

\section{REFERENCES}

Abon, C.C., David, C.P.C. and Pellejera, N.E.B. (2011) Reconstructing the tropical storm Ketsana flood event in Marikina River, Philippines. Hydrology and Earth System Sciences, 15, 1283-1289. https://doi.org/10.5194/hess-15-1283-2011.

Akasaka, I., Morishima, W. and Mikami, T. (2007) Seasonal march and its spatial difference of rainfall in the Philippines. International Journal of Climatology, 27(6), 715-725. https://doi.org/ 10.1002/joc.1428.

Bagtasa, G. (2017) Contribution of tropical cyclones to rainfall in the Philippines. Journal of Climate, 30(10), 3621-3633. https:// doi.org/10.1175/JCLI-D-16-0150.1.

Bagtasa, G. (2019). Enhancement of summer monsoon rainfall by tropical cyclones in northwestern Philippines. Journal of the Meteorological Society of Japan. Ser. II. https://doi.org/10.2151/ jmsj.2019-052, 97, 967, 976

Bagtasa, G. (2020) Influence of Madden-Julian oscillation on the intraseasonal variability of summer and winter monsoon rainfall in the Philippines. Journal of Climate, 33(22), 9581-9594. https://doi.org/10.1175/JCLI-D-20-0305.1.

Bonapace, T., Srivastava, S. and Mohanty, S. (2012) "Asia-pacific disaster report 2012: reducing vulnerability and exposure to disasters, United Nations ESCAP.” Available at: http://www.unisdr.org/we/ inform/publications/29288 [Accessed 1st August 2020].

Bowman, K.P. and Fowler, M.D. (2015) The diurnal cycle of precipitation in tropical cyclones. Journal of Climate, 28(13), 53255334. https://doi.org/10.1175/JCLI-D-14-00804.1.

Camargo, S.J. and Hsiang, S.M. (2015) Tropical cyclones: from the influence of climate to their socioeconomic impacts. In: Chavez, M., Ghil, M. and Urrutia-Fucugauchi, J. (Eds.) Geophysical Monograph Series. Hoboken, NJ: John Wiley and Sons, Inc, pp. 303-342.

Cayanan, E.O., Chen, T.-C., Argete, J.C., Yen, M.-C. and Nilo, P.D. (2011) The effect of tropical cyclones on southwest monsoon 
rainfall in the Philippines. Journal of the Meteorological Society of Japan, 89A, 123-139. https://doi.org/10.2151/jmsj.2011-A08.

Cheung, K., Huang, L.-R. and Lee, C.-S. (2008) Characteristics of rainfall during tropical cyclone periods in Taiwan. Natural Hazards and Earth System Sciences, 8(6), 1463-1474. https:// doi.org/10.5194/nhess-8-1463-2008.

Cheung, K., Yu, Z., Elsberry, R.L., Bell, M. and Tsuboki, K. (2018) Recent advances in research and forecasting of tropical cyclone rainfall. Tropical Cyclone Research and Review, 7(2), 106-126. https://doi.org/10.6057/2018TCRR02.03.

Chia, H.H. and Ropelewski, C.F. (2002) The interannual variability in the genesis location of tropical cyclones in the Northwest Pacific. Journal of Climate, 15(20), 2934-2944.

Cinco, T.A., de Guzman, R.G., Ortiz, A.M.D., Delfino, R.J.P. and Ares, E.D. (2016) Observed trends and impacts of tropical cyclones in the Philippines. International Journal of Climatology, 36(14), 4638-4650. https://doi.org/10.1002/joc.4659.

Corporal-Lodangco, I.L. and Leslie, L.M. (2016) Cluster analysis of Philippine tropical cyclone climatology: applications to forecasting. Journal of Climatology and Weather Forecasting, 04(01). https://doi.org/10.4172/2332-2594.1000152.

Corporal-Lodangco, I.L., Leslie, L.M. and Lamb, P.J. (2016) Impacts of ENSO on Philippine tropical cyclone activity. Journal of Climate, 29(5), 1877-1897. https://doi.org/10.1175/JCLI-D-1400723.1.

Cruz, F.T., Narisma, G.T., Villafuerte, M.Q., Cheng Chua, K.U. and Olaguera, L.M. (2013) A climatological analysis of the southwest monsoon rainfall in the Philippines. Atmospheric Research, 122, 609-616. https://doi.org/10.1016/j.atmosres.2012. 06.010 .

David, C.P.C., Racoma, B.A.B., Gonzales, J. and Clutario, M.V. (2013) A manifestation of climate change? A look at Typhoon Yolanda in relation to the historical tropical cyclone archive. Science Diliman, 25(2), 78-85.

Diffenbaugh, N.S., Pal, J.S., Trapp, R.J. and Giorgi, F. (2005) Finescale processes regulate the response of extreme events to global climate change. Proceedings of the National Academy of Sciences, 102(44), 15774-15778. https://doi.org/10.1073/pnas.0506042102.

Ding, Y. and Chan, J.C.L. (2005) The east Asian summer monsoon: an overview. Meteorology and Atmospheric Physics, 89(1-4), 117-142. https://doi.org/10.1007/s00703-005-0125-z.

Emanuel, K. (2017) Assessing the present and future probability of hurricane Harvey's rainfall. Proceedings of the National Academy of Sciences, 114(48), 12681-12684. https://doi.org/10.1073/ pnas.1716222114.

Fujiwhara, S. (1923) On the growth and decay of vortical systems. Quarterly Journal of the Royal Meteorological Society, 49(206), 75-104. https://doi.org/10.1002/qj.49704920602.

Gray, W.M. (1977) Tropical cyclone genesis in the Western North Pacific. Journal of the Meteorological Society of Japan. Ser. II, 55(5), 465-482. https://doi.org/10.2151/jmsj1965.55.5_465.

Guo, L., Klingaman, N.P., Vidale, P.L., Turner, A.G. and Cobb, A. (2017) Contribution of tropical cyclones to atmospheric moisture transport and rainfall over East Asia. Journal of Climate, 30(10), 3853-3865. https://doi.org/10.1175/JCLI-D-16-0308.1.

Hsu, L.-H., Kuo, H.-C. and Fovell, R.G. (2013) On the geographic asymmetry of Typhoon translation speed across the Mountainous Island of Taiwan. Journal of the Atmospheric Sciences, 70(4), 1006-1022. https://doi.org/10.1175/JAS-D-12-0173.1.
Huffman, G.J., Bolvin, D.T., Nelkin, E.J., Wolff, D.B. and Stocker, E.F. (2007) The TRMM multisatellite precipitation analysis (TMPA): quasi-global, multiyear, combined-sensor precipitation estimates at fine scales. Journal of Hydrometeorology, 8(1), 38-55. https://doi.org/10.1175/JHM560.1.

Jamandre, C.A. and Narisma, G.T. (2013) Spatio-temporal validation of satellite-based rainfall estimates in the Philippines. Atmospheric Research, 122, 599-608. https://doi.org/10.1016/j. atmosres.2012.06.024.

Kim, I.-W., Oh, J., Woo, S. and Kripalani, R.H. (2019) Evaluation of precipitation extremes over the Asian domain: observation and modelling studies. Climate Dynamics, 52(3-4), 1317-1342. https://doi.org/10.1007/s00382-018-4193-4.

Knapp, K. R., Diamond, H. J., Kossin, J. P., Kruk, M. C. and Schreck, C. J. (2018) International Best Track Archive for Climate Stewardship (IBTrACS) Project, Version 4. [Western Pacific basin]. NOAA National Centers for Environmental Information. non-government domain. [Accessed 1st October 2019] from https://doi.org/10.25921/82ty-9e16

Knapp, K.R., Kruk, M.C., Levinson, D.H., Diamond, H.J. and Neumann, C.J. (2010) The international best track archive for climate stewardship (IBTrACS): unifying tropical cyclone best track data. Bulletin of the American Meteorological Society, 91, 363-376. https://doi.org/10.1175/ 2009BAMS2755.1.

Knutson, T.R., McBride, J.L., Chan, J., Emanuel, K. and Sugi, M. (2010) Tropical cyclones and climate change. Nature Geoscience, 3(3), 157-163. https://doi.org/10.1038/ngeo779.

Koide, N., Robertson, A.W., Ines, A.V.M., Qian, J.-H. and Lucero, A. (2013) Prediction of rice production in the Philippines using seasonal climate forecasts. Journal of Applied Meteorology and Climatology, 52(3), 552-569. https://doi.org/10. 1175/JAMC-D-11-0254.1.

Kossin, J.P. (2018) A global slowdown of tropical-cyclone translation speed. Nature, 558(7708), 104-107. https://doi.org/10.1038/ s41586-018-0158-3.

Kruskal, W.H. and Wallis, W.A. (1952) Use of ranks in one- criterion variance analysis. Journal of the American Statistical Association., 47(260), 583-621. https://doi.org/10.1080/01621459. 1952.10483441.

Kubota, H. and Wang, B. (2009) How much do tropical cyclones affect seasonal and interannual rainfall variability over the Western North Pacific? Journal of Climate, 22(20), 5495-5510. https://doi.org/10.1175/2009JCLI2646.1.

Lagmay, A.M.F., Bagtasa, G., Crisologo, I.A., Racoma, B.A.B. and David, C.P.C. (2015) Volcanoes magnify metro Manila's southwest monsoon rains and lethal floods. Frontiers in Earth Science, 2. https://doi.org/10.3389/feart.2014.00036.

Lagmay, M. and Racoma, B.A. (2019) Lessons from tropical storms Urduja and Vinta disasters in the Philippines. Disaster Prevention and Management, 28(2), 154-170. https://doi.org/10.1108/ DPM-03-2018-0077.

Lai, Y., Li, J., Gu, X., Chen, Y.D. and Wu, G. (2020) Greater flood risks in response to slowdown of tropical cyclones over the coast of China. Proceedings of the National Academy of Sciences, 117(26), 14751-14755. https://doi.org/10.1073/pnas.19189 87117.

Lansigan, F.P., de los Santos, W.L. and Coladilla, J.O. (2000) Agronomic impacts of climate variability on rice production in the 
Philippines. Agriculture, Ecosystems and Environment, 82(1-3), 129-137. https://doi.org/10.1016/S0167-8809(00)00222-X.

Lanzante, J.R. (2019) Uncertainties in tropical-cyclone translation speed. Nature, 570, E6-E15. https://doi.org/10.1038/s41586019-1223-2.

Leppert, K.D. and Cecil, D.J. (2016) Tropical cyclone diurnal cycle as observed by TRMM. Monthly Weather Review, 144(8), 27932808. https://doi.org/10.1175/MWR-D-15-0358.1.

Minamide, M. and Yoshimura, K. (2014) Orographic effect on the precipitation with Typhoon Washi in the Mindanao Island of the Philippines. Scientific Online Letters on the Atmosphere, 10, 67-71. https://doi.org/10.2151/sola.2014-014.

Moon, I.J., Kim, S.H. and Chan, J.C.L. (2019) Climate change and tropical cyclone trend. Nature, 570, E3-E5. https://doi.org/10. 1038/s41586-019-1222-3.

NASA JPL. (2020). NASADEM Merged DEM Global 1 Arc Second V001 [Data Set]. NASA EOSDIS Land Processes DAAC. [Accessed 10th July 2020] from https://doi.org/10.5067/ MEaSUREs/NASADEM/NASADEM_HGT.001

Nesbitt, S.W. and Zipser, E.J. (2003) The diurnal cycle of rainfall and convective intensity according to three years of TRMM measurements. Journal of Climate, 16, 20-1475.

O'Neill, M.E., Perez-Betancourt, D. and Wing, A.A. (2017) Accessible environments for diurnal-period waves in simulated tropical cyclones. Journal of the Atmospheric Sciences, 74(8), 24892502. https://doi.org/10.1175/JAS-D-16-0294.1.

Peatman, S.C., Klingaman, N.P. and Hodges, K.I. (2019) Tropical cyclone-related precipitation over the northwest tropical Pacific in met Office global operational forecasts. Weather and Forecasting, 34(4), 923-941. https://doi.org/10.1175/WAF-D-190017.1.

Racoma, B.A.B., David, C.P.C., Crisologo, I.A. and Bagtasa, G. (2016) The change in rainfall from tropical cyclones due to orographic effect of the Sierra Madre mountain range in Luzon, Philippines. Philippine Journal of Science, 145(4), 313-326.

Rios Gaona, M.F. and Villarini, G. (2018) Characterization of the diurnal cycle of maximum rainfall in tropical cyclones. Journal of Hydrology, 564, 997-1007. https://doi.org/10.1016/j.jhydrol. 2018.07.062.

Rodolfo, K.S., Lagmay, A.M.F., Eco, R.C., Herrero, T.M.L. and Santiago, J.T. (2016) The December 2012 Mayo River debris flow triggered by Super Typhoon Bopha in Mindanao, Philippines: lessons learned and questions raised. Natural Hazards and Earth System Sciences, 16(12), 2683-2695. https://doi. org/10.5194/nhess-16-2683-2016.
Tropical Rainfall Measuring Mission (TRMM). (2011). TRMM (TMPA) Rainfall Estimate L3 3 hour 0.25 degree $\mathrm{x} 0.25$ degree V7, Greenbelt, MD, Goddard Earth Sciences Data and Information Services Center (GES DISC). [Accessed 5th February 2021], https://doi.org/10.5067/TRMM/TMPA/3H/7

Weather. (2001). Disaster Prevention and Management, 10(4). https://doi.org/10.1108/dpm.2001.07310dac.003.

World Bank. (2015). Agricultural land (\% of land area) Philippines. Food and Agriculture Organization. Subset used: Philippines. Available at: https://data.worldbank.org/indicator/ AG.LND.AGRI.ZS?locations=PH [Accessed 1st May 2020].

Wu, Q., Ruan, Z., Chen, D. and Lian, T. (2015) Diurnal variations of tropical cyclone precipitation in the inner and outer rainbands: diurnal variations of TC precipitation. Journal of Geophysical Research: Atmospheres, 120(1), 1-11. https://doi. org/10.1002/2014JD022190.

Xiang, B., Wang, B., Yu, W. and Xu, S. (2013) How can anomalous western North Pacific subtropical high intensify in late summer? Geophysical Research Letters, 40, 2349-2354. https://doi. org/10.1002/grl.50431.

Yamaguchi, M., Chan, J.C.L., Moon, I.-J., Yoshida, K. and Mizuta, R. (2020) Global warming changes tropical cyclone translation speed. Nature Communications, 11(1), 47. https:// doi.org/10.1038/s41467-019-13902-y.

Yatagai, A., Kamiguchi, K., Arakawa, O., Hamada, A. and Kitoh, A. (2012) APHRODITE: constructing a long-term daily gridded precipitation dataset for Asia based on a dense network of rain gauges. Bulletin of the American Meteorological Society, 93(9), 1401-1415. https://doi.org/10.1175/BAMS-D-11-00122.1.

\section{SUPPORTING INFORMATION}

Additional supporting information may be found in the online version of the article at the publisher's website.

How to cite this article: Racoma, B. A. B., Klingaman, N. P., Holloway, C. E., Schiemann, R. K. H., \& Bagtasa, G. (2021). Tropical cyclone characteristics associated with extreme precipitation in the northern Philippines. International Journal of Climatology, 1-18. https:// doi.org/10.1002/joc.7416 